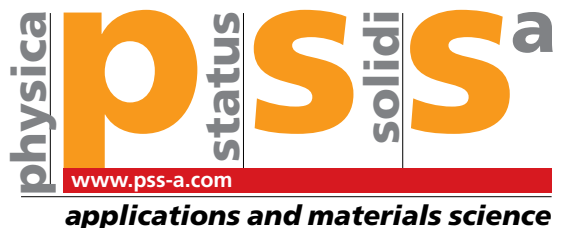

\title{
Diamond-based DNA sensors: surface functionalization and read-out strategies
}

\section{Feature Article}

\author{
Sylvia Wenmackers ${ }^{* *, 1,2}$, Veronique Vermeeren ${ }^{2,3}$, Martin vandeVen $^{2,3}$, Marcel Ameloot $^{2,3}$, \\ Nathalie Bijnens ${ }^{1,2}$, Ken Haenen ${ }^{, 4}$, Luc Michiels ${ }^{2,3}$, and Patrick Wagner ${ }^{*, 1,2}$ \\ ${ }^{1}$ Institute for Materials Research, Hasselt University, Wetenschapspark 1, 3590 Diepenbeek, Belgium \\ ${ }^{2}$ School for Life Sciences, Transnational University Limburg, Agoralaan Building A, 3590 Diepenbeek, Belgium \\ ${ }^{3}$ Biomedical Research Institute, Hasselt University, Agoralaan Building A, 3590 Diepenbeek, Belgium \\ ${ }^{4}$ IMEC vzw, Division IMOMEC, Wetenschapspark 1, 3590 Diepenbeek, Belgium
}

Received 29 August 2008, revised 14 November 2008, accepted 17 November 2008

Published online 26 January 2009

PACS 81.05.Uw, 87.14.gk, 87.64.-t, 87.85.fk

${ }^{*}$ Corresponding author: e-mail patrick.wagner@uhasselt.be, Phone: +32 (0)11 268 895, Fax: +32 (0)11 268899
${ }_{* *}^{*}$ e-mail sylvia.wenmackers@uhasselt.be, Phone: +32 (0)11 268 878, Fax: +32 (0)11 268899

This article reviews the current state-of-the art of diamondbased DNA sensors. Some general concepts involved in biosensors are introduced and applied to DNA sensors. The properties of chemically vapor deposited (CVD) diamond relevant for this application are summed up, with special attention for the stability and bio-compatibility of the material. Several routes to functionalize the diamond surface are considered. The physical properties of the obtained DNA layers are discussed in terms of surface density and molecular conformation. Possible read-out strategies are evaluated, including optical and electronic sensing. With diamond-based DNA sensors, real-time and label-free sensing is achieved.

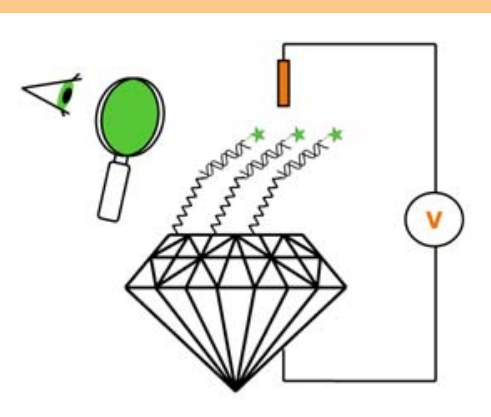

The functionalization of CVD diamond surfaces with DNA is considered for the development of new DNA sensors with optical or electronic read-out.

\section{Introduction}

1.1 DNA sensors A biosensor is a device that uses a biological receptor for the detection of an analyte that usually is (but does not need to be) a biological substance too (Fig. 1). In general, the detection is performed by selective, biological receptors (probes) such as enzymes, antibodies, nucleic acids, membranes or cells, whereas biomimetic sensors use synthetic receptors, such as molecularly imprinted polymers (MIPs). The physical component in a biosensor is called the transducer, and it serves a double function: it has to immobilize the receptors and translate possible recognition events between receptor and target into a physical output signal, most often an optical or electronic signal.
In case of a deoxyribonucleic acid (DNA) sensor, the receptor part consists of end-tethered single stranded (ss) DNA probes (Fig. 1), often referred to as oligonucleotides, or oligos in short. The detection is aimed at indicating whether the target - namely ss-DNA with a base sequence complementary to that of the probes - is present in a sample of unknown test DNA. The complementarity between probe and target DNA provides high sensitivity and specificity to the sensor. It is caused by the principle of base pairing: DNA consists of a sequence of four bases, adenine (A), thymine $(\mathrm{T})$, cytosine $(\mathrm{C})$, and guanine $(\mathrm{G})$, that can be paired as $A=T$, and the more stable $C \equiv G$ pair, involving two and three hydrogen bonds respectively. The binding process is called 'hybridization' and brings about the 
secondary structure of a double stranded (ds) helix, whereas the destruction of the bonds between the strands and the associated duplex-form is called 'denaturation' or 'melting' (by increasing temperature or changing the chemical environment). Most DNA sensors are based on the detection of hybridization.

Regarding the required sensitivity of a DNA sensor, it is worth mentioning that the smallest difference in the primary structure of two DNA strands is a difference in just one base (1-mismatch). If such a point-mutation is prevalent in at least five percent of the population, it is called a single nucleotide polymorphism (SNP) [1]. Many SNPs in many genes have been identified so far. Most of them are silent (without any effect), or cause harmless variations (e.g. affecting eye or hair color), but some are related to diseases (e.g. sickle cell anemia). Hence, the intended sensitivity of a DNA sensor is to distinguish between fully complementary target ss-DNA and 1-mismatch ss-DNA. DNA sensors with SNP-sensitivity can be put to good use, not only for disease diagnosis aimed at defects already known, but also for the discovery and identification of new defects.

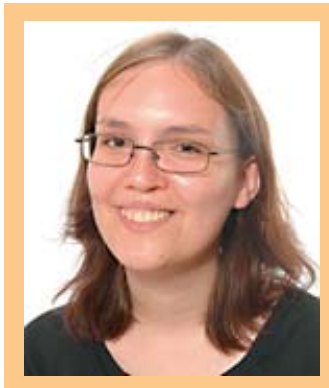

Sylvia Wenmackers was born in 1980 and graduated in 2002 at Ghent University, Belgium with a thesis on the conceptual fundamentals of quantum mechanics. In the same year, she joined the new BIOSensor Group at Hasselt University and defended her Ph.D. in 2008. A central topic of her research is the covalent binding of bio molecules to semiconductor surfaces and optical techniques. An important part of her work was done in close cooperation with the ISAS Institute for Analytical Sciences and the BESSY II synchrotron facility in Berlin.

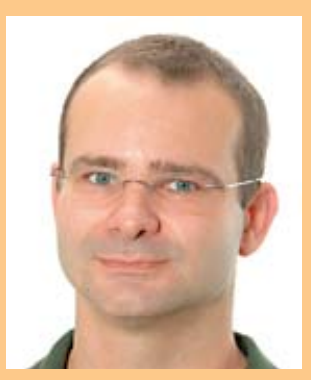

Patrick Wagner was born in 1967 and obtained his Ph.D. from Technical University Darmstadt in 1994 with an experimental thesis on hightemperature superconductors. In 1995, he joined the Laboratory of Solid State Physics and Magnetism at Catholic University Leuven, where he studied magneto transport in mixed-valency magnetic oxides. Since 2001, he is professor of experimental physics at Hasselt University and responsible for the biosensor development with a special focus on DNA- and protein sensors as well as small-molecule detection by molecular imprints.

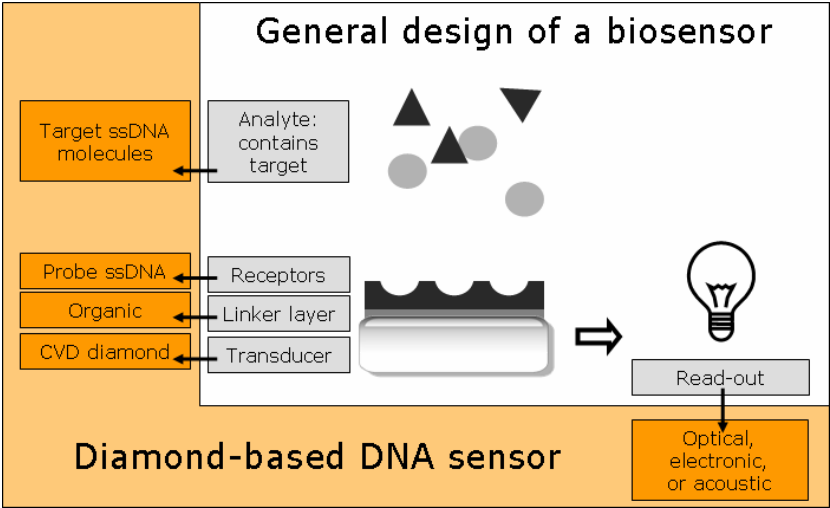

Figure 1 (online colour at: www.pss-a.com) Design of a generic biosensor, with indication of the nature of some parts for the specific case of a diamond-based DNA sensor.

To hold the receptors fixed and to allow the read-out of possible recognition events, the receptors are immobilized onto a physical transducer by physisorption or covalent bonds, usually involving linker molecules. For DNA sensors it is a common approach to produce layers of terminally attached probe ss-DNA molecules onto a solid support (DNA brushes), where they can hybridize to target ss-DNA molecules from solution. However, not all groups attach the probe fragments in head-on configuration: Davis et al. adsorb probe ss-DNA on screen-printed carbonelectrodes coated with polyethylenimine and report good results for the electronic read-out of hybridization events $[2,3]$.

1.2 CVD diamond In addition to commonly used support materials for DNA sensors such as glass, plastic and silicon, chemically vapor deposited (CVD) diamond is an excellent transducer. We present several arguments in support of this statement: we will address the stability and biocompatibility of diamond, and review different surface

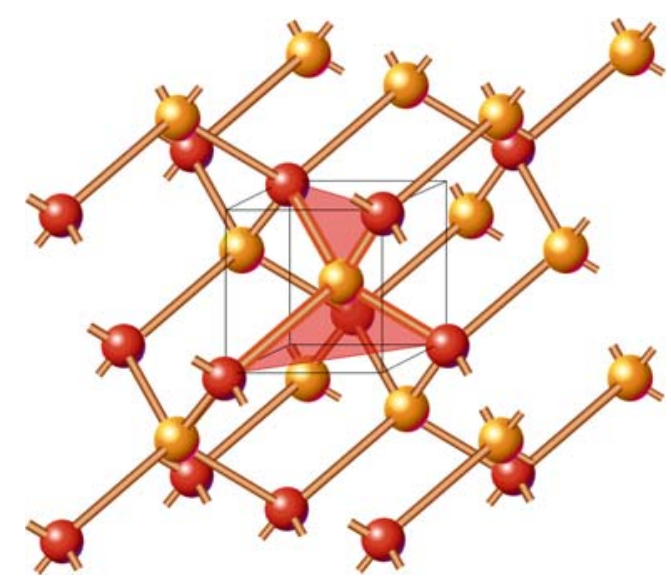

Figure 2 (online colour at: www.pss-a.com) Ball and stick model illustrating the bulk structure of a cubic diamond crystal, $2 \times \mathrm{fcc}$ : the yellow and red positions each form one fcc structure. The $\mathrm{C}-\mathrm{C}$ bond length is $0.154 \mathrm{~nm}$. 
treatments aimed at the introduction of functional groups and DNA. We will also look into the relevant properties of diamond for it to be used successfully as the relevant properties of diamond for it to be used successfully as the transducer of an optical, electronic, or acoustic DNA sensor.

First, we look into some general properties of the material. Natural diamond is a mineral, an allotrope of the element carbon that is formed inside the Earth [4]. Its crystalline structure, $2 \times$ face-centered cubic (fcc), can be seen in Fig. 2. Because mineral diamond is too rare and its properties cannot be tuned, this material is of limited use for scientific and technological applications. However, diamond can also be produced by chemical vapor deposition (CVD) from a carbon-containing process gas, usually methane $\left(\mathrm{CH}_{4}\right)$. This is called a metastable growth method, because growing diamond under the relatively low pressure and temperature conditions involved, requires continuous and selective etching of the more stable graphite deposit. To this aim, a relatively high amount of hydrogen gas $\left(\mathrm{H}_{2}\right)$ is introduced in the plasma [5].

CVD diamond can be mono- or polycrystalline. Whereas monocrystalline diamond requires a diamond substrate (usually obtained from high pressure and high temperature, HPHT, synthesis), polycrystalline diamond can be grown on different materials, such as silicon ( $\mathrm{Si}$ ) and quartz $\left(\mathrm{SiO}_{2}\right)$, and is dominated by columnar growth. For grain sizes below $500 \mathrm{~nm}$, the CVD film is called nanocrystalline diamond (NCD); after a certain thickness, the grain size near the surface exceeds $500 \mathrm{~nm}$ and the film becomes microcrystalline diamond $(\mu-C D)$. The increase of grain size and surface roughness with longer growth times is illustrated with atomic force microscopy (AFM) images in Fig. $3 b-d$. A slightly different material is ultra-nanocrystalline diamond (UNCD) (Fig. 3a): the grain size and roughness are not dependent on the film thickness, because these films do not show columnar growth. The material is grown from a $\mathrm{H}$-poor $/ \mathrm{CH}_{4}$-rich plasma, to achieve an extremely high rate of re-nucleation $[6,7]$. More details on CVD diamond in general can be found in reviews such as [8], or textbooks such as [9-13].

1.3 Stability of CVD diamond in bio-applications Diamond is very inert in diverse chemical environments, which may be beneficial for the development of chemical sensors. For the design of biosensors however, it is also necessary to know what the influence is of diamond on a biological environment. Whereas full biocompatibility is not required for DNA sensors, this property is an important issue for in vivo biosensors: some general advantages of implants covered with diamond coatings are high biotolerance, biocompatibility, corrosion resistance and protection against metalosis (bone infection due to metal implant) [14]. The biocompatibility of CVD diamond was found to be at least equivalent to titanium and stainless steel, two materials commonly used for implants [15]: minimal inflammatory response was observed for both polished and unpolished CVD diamond implants. Also Aspenberg et al. found no foreign body response towards diamond particles with a mean size of $1 \mu \mathrm{m}$ (in contrast to cobalt-chromium-molybdenum debris particles of the same size), and conclude from the observed benign histological reactions that implantation of diamond-coated $\mathrm{SiC}$ is harmless [16]. Both studies addressed only the local influence of diamond-coated implants. Bakowicz et al. performed in vitro and in vivo tests with NCD powders, as a model for possible effects of NCD coatings on distant organs [17]. In the in vitro part, the diamond powders were found to play a protective role in the human body by slowing down free radical toxic reactions that damage cells and tissues (e.g. by inhibiting lipid peroxidation in blood plasma). In the in vivo study with rats, no immune response was observed after 10 days, and a very low reaction was ascertained after 21 days. The powders did not damage structure tissues or proliferation of connective tissue. From this, Bakowicz et al. conclude that NCD coatings are safe for biomedical implants. In a study by Okrój et al. [18], NCD surfaces were found to reduce the adhesion of blood platelets as compared to stainless steel, by reducing the plasma protein adhesion; thus, diamond seems to be an appropriate material to be used in contact with human blood. Schrand et al. studied diamond particles of 2-10 nm, with and without acidic or basic surface modification: they were found to be biocompatible with a variety of cells of different origins, and once inside the cell the nanodiamond particles remained non-reactive [19].

Whereas future in vivo biosensors might clearly benefit from the use of CVD diamond transducers, we come back to our case of in vitro DNA sensors. For DNA sensor applications, it is usually not required to use freestanding
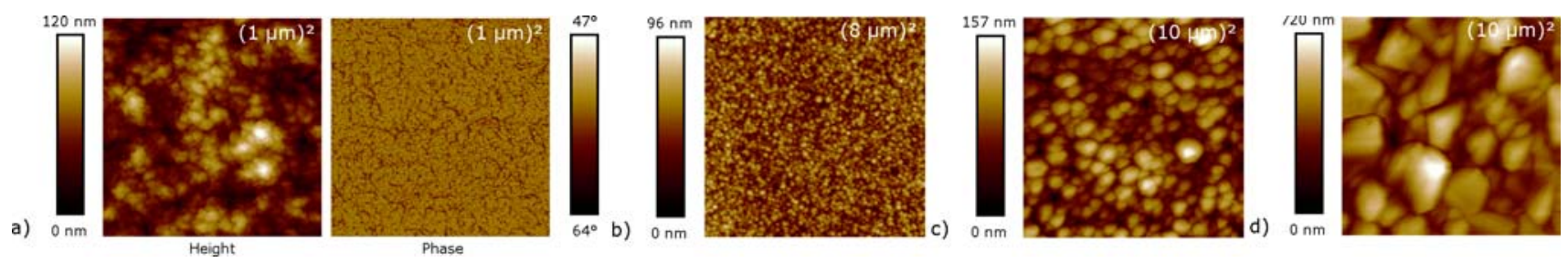

Figure 3 (online colour at: www.pss-a.com) AFM images of H-terminated CVD diamond films under ambient conditions. a) Tapping mode height and phase image of $2 \mu \mathrm{m}$ thick UNCD film with RMS roughness $17 \mathrm{~nm}$. b) -d) Non-contact mode images of polycrystalline diamond: b) NCD surface with RMS roughness $10 \mathrm{~nm}$; c) thicker NCD film with larger grains and RMS roughness $21 \mathrm{~nm}$; d) thicker film which can be regarded as $\mu-C D$, here the RMS roughness is $100 \mathrm{~nm}$. 
diamond: NCD and UNCD films on $\mathrm{Si}$ are easier to produce and cheaper, while the surface exhibits most advantages of the material. Experiments by Yang et al. on photo-chemically modified diamond indicate that the denaturation-hybridization cycle can be repeated on (U)NCD up to 30 times [20]. Our group has confirmed for a different linking method that 35 denaturation-hybridization cycles are possible on NCD [21]. These results imply that diamond-based DNA chips have a superior long-term stability with minor signal loss.

In conclusion, the stability of CVD diamond is a promising option to create an in vivo biosensor, due to the biocompatibility of diamond, or a reusable biosensor for in vitro application, such as a DNA sensor.

2 Functionalization of CVD diamond surfaces Biological molecules and diamond have something essential in common: carbon. Diamond is a covalent crystal form of carbon, whereas the versatile properties of biomolecules - from fatty acids to DNA - are due to the same element. This fact can be used to design stable and reusable DNA sensors: a covalent bond between the outermost carbon atom of a diamond surface and a carbon atom belonging to an organic linker molecule would be a $\mathrm{C}-\mathrm{C}$ bond, which is more stable than a $\mathrm{Si}-\mathrm{C}$ or $\mathrm{Au}-\mathrm{C}$ bond for instance (average binding energies can be found in [22]). (U)NCD-coated silicon was indeed found to be a very stable platform for DNA [20]. Of course, other carbon-containing materials have the same advantage. However, the diamond substrate itself is more stable than its alternatives too, as discussed in the previous section.

The renowned inertness of diamond is not advantageous when it comes to the initial functionalization, demanding extreme chemical conditions. Several routes to efficiently functionalize the diamond surface have been developed nevertheless, as will be reviewed now.

2.1 Hydrogen-terminated and clean (reconstructed) diamond surfaces At the end of the CVD process, the freshly grown diamond film is in contact with a pure hydrogen-plasma. Thus, the dangling bonds are saturated with monovalent $\mathrm{H}$. As an example, the surface reconstructions for an (100) diamond surface are given in Fig. 4. The occurrence of $\mathrm{C}(100) 1 \times 1: 2 \mathrm{H}$ (Fig. $4 \mathrm{a}$ ) surfaces is prevented by steric hindrance; rather mixed $1 \times 1: 2 \mathrm{H}$ and $2 \times 1: \mathrm{H}$ surfaces are to be expected [23].
The double-bonded dimers introduce occupied $\pi$ - and unoccupied $\pi^{*}$-states in the band gap; the dimers are spatially separated from each other, and the surface is non-metallic. For the $(111)$ surface, we mention the Pandey $(2 \times 1)$ reconstruction [24]: the $C$ atoms at the uppermost positions form zigzag chains, $\pi$-bonded as in graphite, and the surface becomes semi-metallic.

The H-termination ('hydrogenation') of a diamond surface is very stable in ambient air, in contrast to Si for instance. A diamond sample that has been surface-modified for experiments can be cleaned by putting it in a strongly oxidizing environment and back in an H-plasma afterwards. $\mathrm{H}$-terminated diamond is very hydrophobic: water contact angles around $90^{\circ}$ and higher are reported for $\mathrm{H}$-terminated $\mu-C D, N C D$ and UNCD surfaces [25-27]. Also the electronic properties are quite extraordinary and of interest for sensing applications, as will be described further on.

2.2 Oxidized diamond surfaces Hydrogen-terminated diamond in air at room temperature (RT) will not spontaneously oxidize. Oxidized diamond surfaces can be obtained however from oxygen plasma, ozone $\left(\mathrm{O}_{3}\right)$ treatment or wet chemical treatments. An example of the latter is by a mixture of boiling sulfuric acid $\left(\mathrm{H}_{2} \mathrm{SO}_{4}\right)$ and potassium nitrate $\left(\mathrm{KNO}_{3}\right)$. Once the reaction of $\mathrm{H}_{2} \mathrm{SO}_{4}$ with $\mathrm{KNO}_{3}$ starts, a fume of nitric acid $\left(\mathrm{HNO}_{3}\right)$ escapes, another strong acid and oxidizing agent. Alternatively, H-terminated diamond can be oxidized locally by AFM using negatively biased $\mathrm{Au}[28]$ or Si cantilevers [29, 30]. According to Ando et al. [31], heating hydrogenated diamond in an $\mathrm{O}_{2}$ environment above $300{ }^{\circ} \mathrm{C}$ oxidizes diamond (with $\mathrm{C}=\mathrm{O}$ and $\mathrm{C}-\mathrm{O}-\mathrm{C}$ groups), while diamond starts to burn in $20 \% \mathrm{O}_{2}$ above $480{ }^{\circ} \mathrm{C}$. Based on wettability studies, it was shown by Larsson et al. that oxidation by mixtures of $\mathrm{O}_{2}$ and $\mathrm{H}_{2} \mathrm{O}$ becomes efficient from temperatures of $450{ }^{\circ} \mathrm{C}$ and up, whereas for pure $\mathrm{O}_{2}$ temperatures higher than $500{ }^{\circ} \mathrm{C}$ are required [32]; in their paper, also a molecular dynamics study modeling these oxidation processes is presented. The oxidation rate depends on the crystalline orientation and increases from (100) over (110) to (111) [33]. However, heating diamond to temperatures above $1000{ }^{\circ} \mathrm{C}$ in vacuum or in an atmosphere of inert argon is found to cause graphitization [33, 34].

For the $(100)-(1 \times 1)$ : O surface, e.g. obtained from plasma treatment, the two most-plausible arrangements are the "ether" or "bridge", and "ketone" or "carbonyl" con-

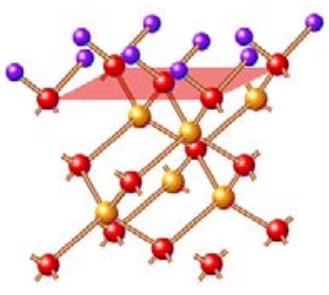

a) $\mathrm{C}(100) 1 \times 1: 2 \mathrm{H}$

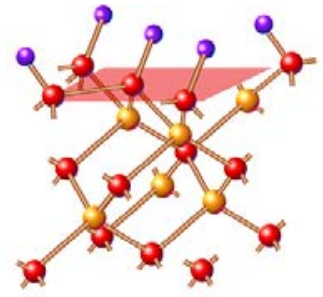

b) $\mathrm{C}(100) 2 \times 1: \mathrm{H}$

Legend: $\bullet$ and $\odot$ atoms; $\bullet=\mathrm{H}$ atom

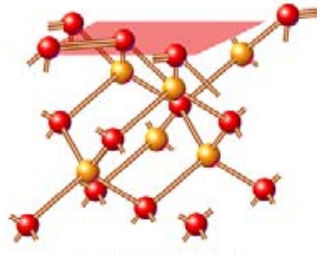

c) $\mathrm{C}(100) 2 \times 1$
Figure 4 (online colour at: www.pss-a.com) Surface reconstructions on the (100) diamond surface. 


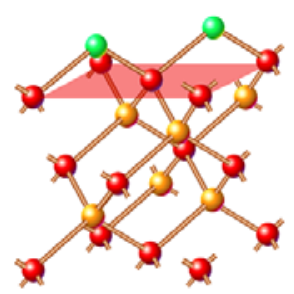

a) $\mathrm{C}(100) 1 \times 1: \mathrm{O}$ ether

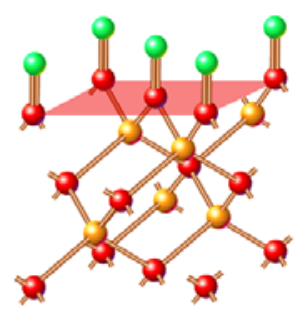

b) $\mathrm{C}(100) 1 \times 1: 0$ ketone

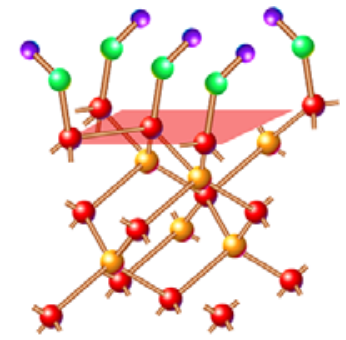

c) $\mathrm{C}(100) 2 \times 1: \mathrm{OH}$

Legend: $\bullet$ and $\odot=\mathrm{C}$ atoms; $\bullet=\mathrm{O}$ atom; $\bullet=\mathrm{H}$ atom

Figure 5 (online colour at: www.pss-a.com) Two most plausible $(100)-(1 \times 1)$ : $\mathrm{O}$ surfaces are shown in a) and b). An $\mathrm{OH}$ terminated diamond (100) surface is given in c).

figuration [35]. In the "ether" or "bridge" arrangement, the $\mathrm{O}$ atom bridges two surface $\mathrm{C}$ atoms and makes a single bond to each $(\mathrm{C}-\mathrm{O}-\mathrm{C})$ (Fig. 5a). In the ketone conformation, the $\mathrm{O}$ atom is double-bonded to a single surface $\mathrm{C}$ atom $(\mathrm{C}=\mathrm{O})$, with the axis of this carbonyl group normal to the surface (Fig. 5b). According to Sque et al., the highest occupied molecular orbital (HOMO) level in the bridge configuration is significantly lower than that in the ketone system, making the bridge system the more stable one (although the ketone system may be metastable) [36].

For chemically oxidized diamond surfaces, additional oxygen containing species are expected, such as hydroxyl $(-\mathrm{OH})$ (Fig. 5c) and carboxyl (-COOH) [37]. These groups are responsible for the hydrophilic character of oxidized diamond surfaces: water contact angles of $45^{\circ}$ and lower are reported for $\mu-C D, N C D$ and UNCD in [25-27]. By deconvolution of the oxygen peak observed by X-ray photo-electron spectroscopy (XPS), we have studied the oxides on single crystalline diamond in some detail [26]. With the reservation that the deconvolution and the assignment of the peaks remains arbitrary to a certain degree, we estimated that $65.0 \%$ of all oxygen was present in the form ofcarbonyl and hydroxyl (also as part of carboxyl) (with peak position at $531.0 \mathrm{eV}$ ) $; 12.0 \%$ of the peak intensity was due to oxygen in bridge structures (at $531.9 \mathrm{eV}$ ); the abundance of double-bonded oxygen atoms in carboxyl was estimated to be $14.5 \%$ (at $532.8 \mathrm{eV}$ ); and oxygen in other forms accounts for the other $8.5 \%$ (at $533.9 \mathrm{eV}$ ).

\subsection{Reaction of halogens to diamond surfaces}

Several methods have been developed to introduce various other groups on the diamond surface. In particular, the termination of CVD diamond by halogens - fluorine and the larger chlorine - has received some attention in literature. Because H-terminated diamond surfaces are not very reactive, whereas oxidized surfaces are less well-defined (in that they exhibit a mixture of O-containing groups) chlorinated surfaces are interesting intermediates for further functionalization.

Monofluoride termination of $\mathrm{H}$-free diamond (100) and (111) surfaces has been achieved by Freedman [38] by exposure to beams of atomic $F$ in vacuum: atomic $F$ breaks surface dimer bonds in a similar way as H-atoms. A similar treatment with beams of chlorine results in a weak chemisorption of $\mathrm{Cl}$ on diamond (100) surfaces
[38]. The chemisorption of $\mathrm{F}, \mathrm{Cl}, \mathrm{HF}$, and $\mathrm{HCl}$ on (100) diamond has subsequently been described by an $a b$ initio study of Hukka et al. [39]. Hadenfeldt and Benndorf have experimentally observed that $\mathrm{F}$ and $\mathrm{Cl}$ uptake on a (100) surface can be increased substantially by starting with an H-terminated surface [40].

A second approach to obtain Cl-termination has been proposed by Miller and Brown [41, 42]: they use an Hg-arc lamp for the ultraviolet (UV) illumination of H-terminated polycrystalline diamond and diamond powders in $\mathrm{Cl}_{2}$. In a subsequent step, the chlorinated surface is UV illuminated under ammonia $\left(\mathrm{NH}_{3}\right)$ to obtain amine-modified diamond $\left(-\mathrm{NH}_{2}\right.$ termination). Later, Miller also achieved thiolmodification (-SH termination) by using $\mathrm{H}_{2} \mathrm{~S}$ instead of $\mathrm{NH}_{3}$ [43].

Ando et al. reported the fluorination of diamond surfaces using $\mathrm{CF}_{4}$ plasma [31] and $\mathrm{F}_{2}$ molecules [44]. Chlorinated diamond is obtained by thermal reaction of H-terminated diamond with molecular chlorine $\left(\mathrm{Cl}_{2}\right)$ [45]. This is used as an intermediate to obtain hydroxyl groups ( $-\mathrm{OH}$ termination) by treatment with water vapor at $\mathrm{RT}$, amino groups by treatment with $\mathrm{NH}_{3}$ at $425^{\circ} \mathrm{C}$, and $-\mathrm{CF}$ groups by treatment with $\mathrm{CHF}_{3}$ at $600{ }^{\circ} \mathrm{C}$. The thermal reaction of $\mathrm{H}$-terminated diamond with atomic chlorine $\mathrm{Cl}$ was introduced by Chaney and Feigerle [46]: a strong preference of $\mathrm{Cl}$ to chemisorb on (100) diamond is reported. The influence of temperature during the thermal amination process has been further evaluated by Sotowa et al. [47].

A fourth method to chlorinate diamond, by treatment with sulfuryl chloride in chloroform at $50{ }^{\circ} \mathrm{C}$, was used by Ikeda et al. [48]. A small fraction of butyl groups was introduced on the surface, by subsequent reaction of butyllithium dissolved in tetrahydrofuran at $30^{\circ} \mathrm{C}$.

The four methods mentioned so far, all start from clean or H-terminated diamond. In contrast, the reaction of silane coupling reagents with oxidized diamond was reported by Tsubota et al. [49].

Oxidized diamond powders were treated with thionyl chloride $\left(\mathrm{SOCl}_{2}\right)$, and subsequently with thymidine and pyridine to introduce thymidine on the surface, to which DNA could be ligated, according to Ushizawa et al. [50]. Our group tested the straightforward application of this thymidine-recipe for the covalent immobilization of dsDNA on solid $\mu-C D$ films $[26,51]$, rather than diamond 


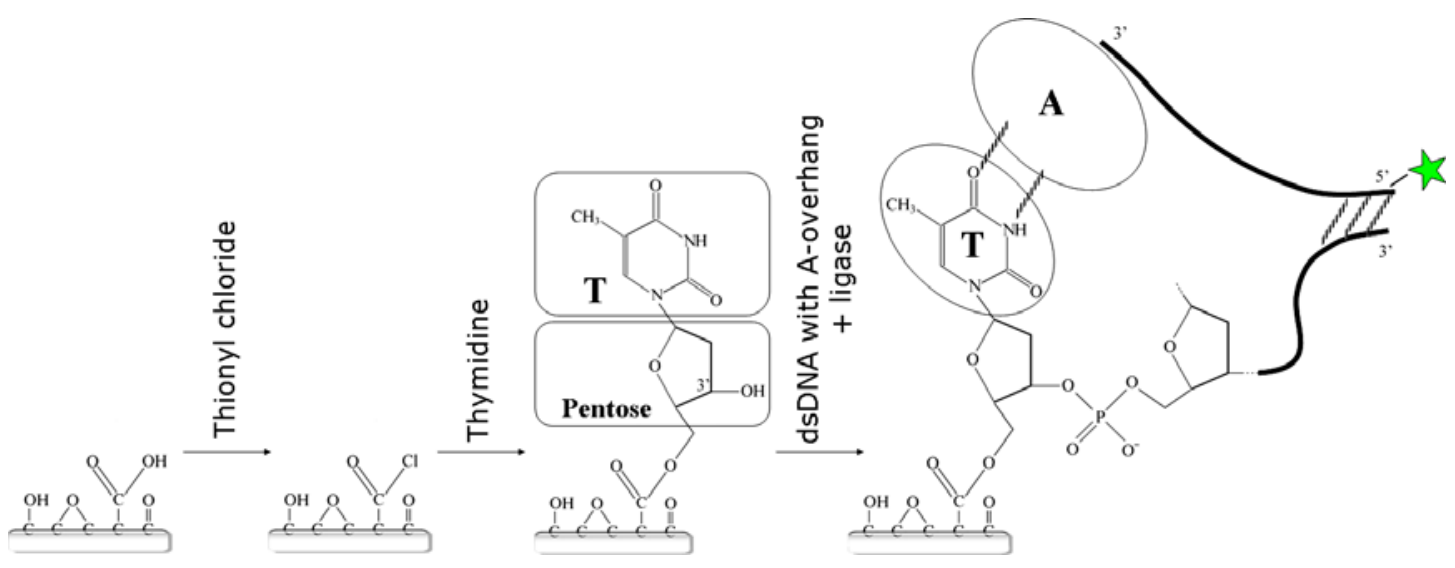

Figure 6 (online colour at: www.pss-a.com) Schematic view of the thymidine-route for attachment of dsDNA to diamond [26, 51]. After wet chemical oxidation, carboxylic acid is presumed to be present: the $\mathrm{OH}$ group is first substituted with a $\mathrm{Cl}$ group, then by thymidine. The A-overhang of a dsDNA PCR-fragment is covalently coupled to the diamond surface by ligation. The star at the unbound 5 '-end denotes a fluorescent label. (Not drawn to scale.)

powders. The intended result of the different process steps can be seen in Fig. 6. The dsDNA was labeled with fluorescein isothiocyanate (FITC) as well as digoxigenin (DIG) for evaluation by confocal fluorescence microscopy and a version of enzyme-linked immunosorbent assay (ELISA) adapted for diamond [26], respectively.

After the modification steps with thionyl chloride and thymidine, a layer of soft material is deposited on the diamond surface, as is evidenced by contact mode AFM images [52]; the irregular structures observed there are probably not beneficial for homogeneous coverage with DNA. Upon introduction of FITC-labeled 250 bp dsDNA, confocal fluorescence microscopy results seem to indicate that the binding is successful. However, after washing the surface with $2 \times$ saline sodium citrate (SSC), the results of both the functionality test with ELISA and fluorescence microscopy were negative.

We can envisage two possible reasons for the lack of success with the thymidine-route on solid supports. First, it is likely that the initial oxidation of the diamond surface is more efficient to introduce a sufficient amount of $\mathrm{COOH}$ groups on diamond powder, than on the surface of diamond films. XPS reveals that only a low amount of required $\mathrm{COOH}$ groups is present on a $\mu-\mathrm{CD}$ surface after oxidation in heated $\mathrm{H}_{2} \mathrm{SO}_{4}$ and $\mathrm{KNO}_{3}$ : carboxyl groups account for $14.5 \%$ of the oxygen present on the diamond surface. The formation of carboxyl requires three dangling bonds: so the concerned carbon atom cannot be $\mathrm{sp}^{3}$-hybridized; it has to be an ad-atom, not part of the diamond lattice. It could well be that grains of diamond show more defects, more carbon atoms with three dangling bonds, and thus more carboxylic groups after oxidation. However, since we failed to attach ds-DNA to NCD as well, this hypothesis does not seem very plausible.

Second, even if the initial amount of carboxylic groups is enough, the ligase might not be working properly close to a solid support, whereas it can 'wrap around' small grains. In case of a solid support, the DNA molecules could be physically adsorbed on the surface, making H-bonds with thymidine, but without making covalent bonds.

In any case, the thymidine link employed in this method is rather short in comparison with e.g. the aminelinker consisting of a sequence of 10 carbon atoms used in [20] and in our own later work [21]. The choice of such a short link could possibly facilitate electronic read-out of hybridization events via the underlying substrate. The use of a longer link on the other hand could make denaturation and rehybridization more probable (higher steric freedom).

2.4 Organic linker molecules attached to diamond surfaces UV illumination cannot only be used for the Cl-termination of diamond [41, 42]: various alkenes can be introduced onto the diamond surface via UV irradiation of H-terminated diamond as well [53], by covering the surface with liquid films of the appropriate alkenes; this technique was used to prepare diamond surfaces terminated with carboxyl and amino groups. This reaction is similar to the introduction of alkenes on H-terminated silicon surfaces, where the reaction can be induced thermally, or by visible (VIS) or UV light [54-56], which allows photo-patterning [57]. Yang et al. published a similar method for covalent DNA attachment on NCD and UNCD surfaces [20]. In their approach, vinyl groups of organic molecules (10-aminodec-1-ene protected by trifluoroacetamide, TFAAD) were UV-linked to the H-terminated diamond surface, by $254 \mathrm{~nm}$ light of $0.35 \mathrm{~mW} / \mathrm{cm}^{2}$ intensity. After a deprotection step, thiolmodified DNA could be tethered to (U)NCD surfaces, applying the intercalating crosslinker sulfosuccinimidyl 4-N-maleimidomethyl cyclohexane-1-carboxylate (SSMCC) (Fig. 7a).

We developed a simpler variation of this scheme in 2005 $[21,58]$. In this route (Fig. 7b), carboxylic acid groups are introduced on the surface directly, by photo-attachment of 10-undecenoic acid (UA) (so no de-protection step is re- 


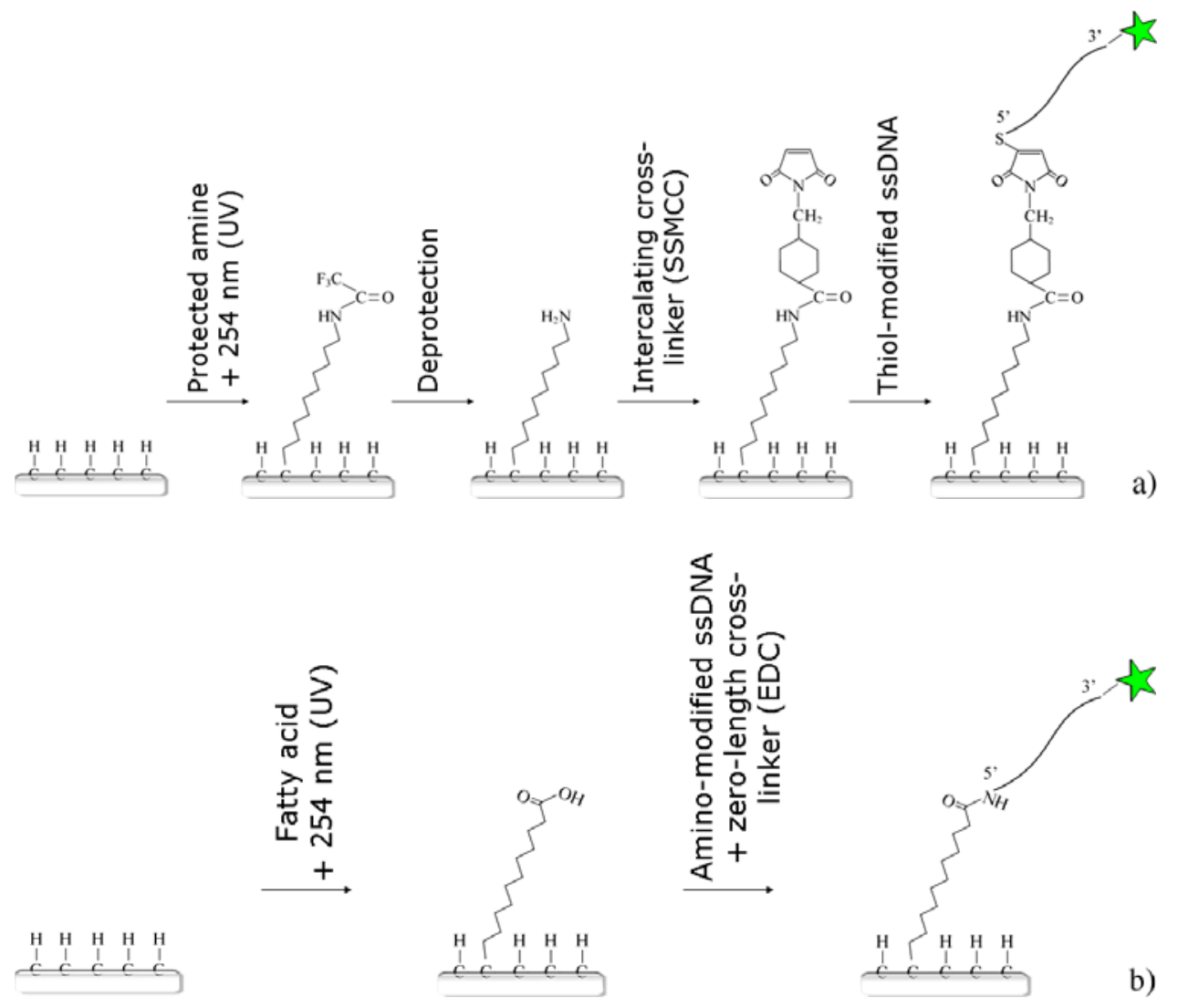

Figure 7 (online colour at: www.pss-a.com) Photo-attachment of organic linker molecules to hydrogenated diamond surfaces, followed by covalent coupling of ssDNA. a) Original method published in [20], involving four process steps. b) Simplified method published in [21], requiring only two process steps. (The respective molecules are not drawn to scale.)

quired), after which the zero-length (non-intercalating) crosslinker 1-ethyl-3-(3-dimethylaminopropyl)-carbodiimide (EDC) is applied to covalently couple amino-modified probe DNA to the pre-treated diamond surface. Next, the DNA probe length and concentration, and the washing steps have been optimized [59]. Short ssDNA probes (8$36 \mathrm{~b}$ ) were found to be more efficient than longer probes $(250 \mathrm{~b})$, confirming the findings in [60], and applied probe concentrations of $300 \mathrm{pmol} / \mathrm{cm}^{2}$ were found to yield optimal probe surface density. Hot acetic acid was found to be most efficient in removing excess UA-linker molecules after the photo-reaction, and $2 \times$ SSC containing $0.5 \%$ sodium dodecyl sulfate (SDS) was best to remove excess probe DNA after the EDC-step.

Three important advantages of the original method developed by Yang et al. [20] are retained by this simpler version: the establishment of a stable carbon-carbon bond between the diamond surface and the organic linker molecule, the tunable linker length, and the possibility of straightforward patterning of the probe DNA layer by use of shadow masks during the photo-attachment of the linker layer, as we have shown in [59]. Excellent contrast could be obtained in these photo-patterning experiments (Fig. 8) because the non-illuminated parts on the surface remain $\mathrm{H}$-terminated, and using optimized washing steps no ad- sorption of DNA was observed on H-terminated diamond. The UA-EDC-attachment scheme shown in Fig. $7 \mathrm{~b}$ requires only two process steps (instead of four), all products are readily available, and the simple design of the molecular scaffold between DNA and diamond surface may facilitate electronic signaling when applied in an electronic DNA sensor.
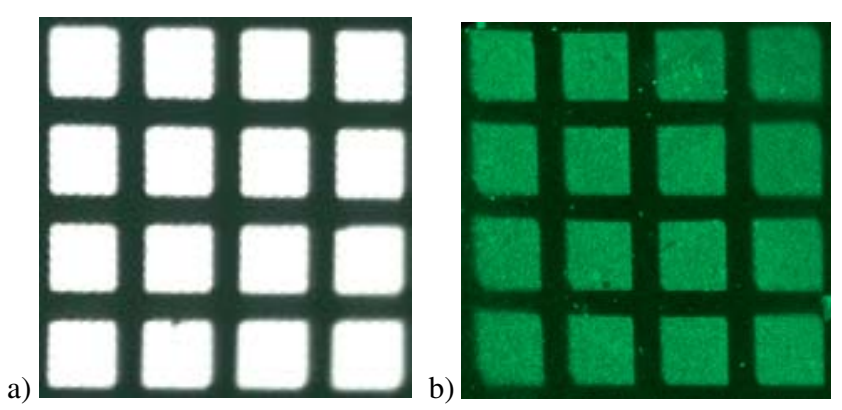

Figure 8 (online colour at: www.pss-a.com) a) Transmission image of grid with $(45 \mu \mathrm{m})^{2}$ open squares and $20 \mu \mathrm{m}$ wide bars, used as shadow mask during photo-attachment of the UA linker layer. b) Fluorescence image of the resulting pattern in the Alexa Fluor 488-labeled $8 \mathrm{~b}$ ssDNA layer on UNCD. Both images show an area of $\sim(245 \mu \mathrm{m})^{2}$. 
This method proved to be very reproducible and has been repeated successfully by Zhong et al. [61]: in their publication it was also shown that the photo-attachment of UA does not improve by the use of trifluoroethyl as a protective headgroup. In the meantime, we have shown that the UA-EDC-method for DNA functionalization is also applicable to $\mathrm{Si}(100)$ [27].

The principle behind the sub-band gap UV activation of H-terminated diamond surfaces is currently still under discussion. Here an attempt is made to summarize what has been elucidated so far. For simplicity, undoped diamond will be considered. The photo-attachment is indeed effective on undoped diamond [62], and because of this electron transport through the bulk can already be excluded. No direct cleavage of the $\mathrm{C}-\mathrm{H}$ bonds under $254 \mathrm{~nm}$ illumination has been observed by Nichols et al. [63]. The H-terminated diamond surface exhibits upward band bending near the surface. Despite this, the energy difference between the valence band (VB) maximum and conduction band (CB) minimum near the surface is still equal to the bulk band gap of diamond: $E_{\mathrm{BG}}=5.47 \mathrm{eV}$. Clearly the UV photons (of $254 \mathrm{~nm}$ or $4.88 \mathrm{eV}$ ) do not possess enough energy to excite $\mathrm{VB}$ electrons into the $\mathrm{CB}$, where they could be emitted (above the vacuum energy level, due to negative electron affinity, NEA) and cause a chemical reaction.

In the paper by Nichols et al. [63], two different pathways were envisaged for electronic ejection into the alkene containing liquid phase: either excitation from surface states, slightly above the VB, to the $\mathrm{CB}$, followed by diffusion and emission, or direct photo-emission from the VB to the vacuum level, without passing through the conduction band. In their article, they also presented the energy levels of the alkene molecule TFAAD used in the route of Fig. 7a: the unoccupied $\pi^{*}$-states of this molecule are found to have an energy almost equal to that of the vacuum level. Ab initio density-functional calculations have shown that H-termination introduces "several unoccupied surface states below the bulk conduction band" [36]. In other words: on H-terminated diamond less energy than $E_{\mathrm{BG}}$
$5.47 \mathrm{eV}$ is required to excite electrons from the VB top into those surface states. Based on this finding, Shin et al. conclude that the optical excitation of VB electrons, located a maximum $\sim 2 \mathrm{~nm}$ from the outermost surface, into empty, H-induced surface states (with energies slightly above vacuum level) triggers the covalent bonding of alkenes [62]. These states have sub-second life-time; from them, electrons can tunnel into unoccupied $\pi^{*}$-states of liquid phase alkene molecules. Nichols et al. derive that only 1 out of 1000 photo-excited electrons results in surface bonding [63]; Shin et al. report a quantum efficiency of 1 in 1600 [62].

Above articles indicate that the process is possible on $\mathrm{H}$-terminated single crystals. Yet, the higher the $\mathrm{sp}^{2}$-content of the diamond, the more additional surface states are present that allow for excitation into the liquid phase energy levels. Therefore, more alkene molecules can be attached to UNCD than to NCD, $\mu-\mathrm{CD}$, or monocrystalline diamond, respectively.

\subsection{Electrochemically modified diamond sur-}

faces Kuo et al. introduced aromatic groups onto the surface of B-doped diamond by the electrochemical reduction of phenyl diazonium salts on the surface [64]. Diamond powders exposed to $\mathrm{NO}_{2}$ near RT were found to have stably adsorbed RNO $x$ and RO $x$ species (in which R stands for radical) on the surface by Azambre et al. [65]. Also this type of surface functionalization can be applied to the coupling of probe ssDNA to diamond - although limited to the case of B-doped diamond. This was done by Yang et al. [66]: nitrophenyl salt is introduced to the surface by reduction and an amino group is created after further reduction. Once the amino-functionality is present, the covalent attachment of thiol-modified ss-DNA can be realized by the previously discussed method from the same authors [20], i.e. using the intercalating crosslinker SSMCC. The corresponding reaction scheme is depicted in Fig. 9. Although this method does not have the advantage of tunable linker length, it does exhibit a covalent $\mathrm{C}-\mathrm{C}$ bond between diamond and linker.

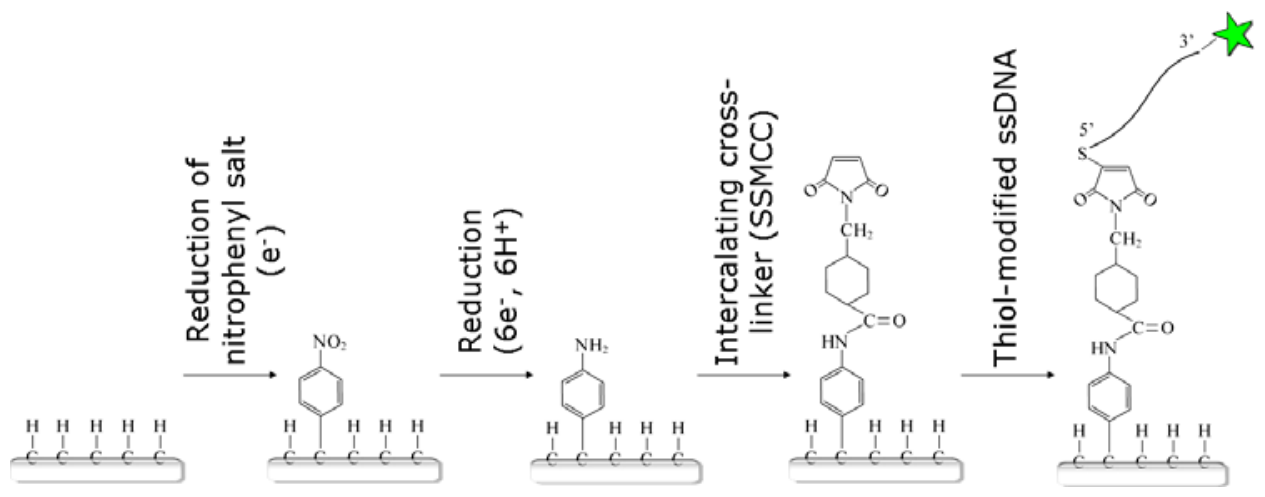

Figure 9 (online colour at: www.pss-a.com) Reduction of nitrophenyl salt at the hydrogenated surface of doped diamond, followed by the coupling of thiol-modified ss-DNA to the amino group on the surface using the intercalating crosslinker SSMCC. (Redrawn from [66]; respective molecules not drawn to scale.) 
Pure chemical grafting of diazonium salts to B-doped diamond has been reported by Shul et al. [67]: in the presence of ionic solvents (instead of an aqueous solution) the reaction does not require thermal or optical activation, nor an external bias. More details on the electrochemical modification of diamond surfaces, including the subsequent introduction of biomolecules other than DNA, can be found in $[68,69]$.

In short, the above surface terminations give sufficient options for the activation of diamond surfaces and the subsequent introduction of biomolecules: once amino-, hydroxyl or carboxyl groups are present on the surface, standard chemical methods involving cross-linkers can be applied to couple almost any biomolecule to the surface. The diamond surface has been functionalized successfully with various biomolecules: not only with DNA as was already discussed, but also with immunoglobulins $\mathrm{G}$ and $\mathrm{M}$ ( $\mathrm{IgG}$ and $\operatorname{IgM}$ ) [70], and enzymes such as catalase [71], urease, glucose, oxidase [72], and horse radish peroxidase [73].

3 Physical properties of DNA layers immobilized on diamond The preparation, characterization and understanding of layers of terminally attached DNA molecules are important factors for improving genetic assays. For good sensor functioning (hybridization), in particular the density and the orientation of the DNA molecules in the sensing layer are important parameters: the DNA layer should have a high density, while avoiding steric hindering, and the orientation of the strands should preferably be perpendicular to the surface. First, some theoretical parameters will be introduced, that allow for the description of the organization of DNA layers. Then, some experimental results of DNA brushes on diamond will be discussed.

3.1 Polymer brushes Polymers in solution can be modeled as worm-like chains (WLC), also called KratkyPorod chains [74]. An important parameter in WLC theory is the persistence length, $l_{\mathrm{p}}$ : it is the length over which the average bend due to thermal excitations equals $1 \mathrm{rad}$. The persistence length is experimentally found to be $\sim 2 \mathrm{~nm}$ for ss-DNA $[75,76]$ and $\sim 50 \mathrm{~nm}$ for dsDNA under physiological conditions [77]. The ratio of the stretched-out DNA length DNA length, $L$, divided by $l_{\mathrm{p}}$ can be regarded as a measure for the flexibility of the molecule: the smaller the fraction, the more it behaves like a stiff rod; if the fraction is considerably higher than unity, the molecule will behave more like a flexible polymer and coil up. The average expansion of a DNA polymer in a solvent can be characterized by its average radius (Fig. 10a): the radius of gyration $\left(R_{\mathrm{g}}\right)$ or Flory radius [78].

$$
R_{\mathrm{g}}=\sqrt{\frac{l_{\mathrm{p}} \cdot L}{3}} .
$$

Equation (1) only holds for (DNA) polymers in a so-called theta-solution [78], in which the polymer conformation can be approximated as a random walk (with a Gaussian distri-

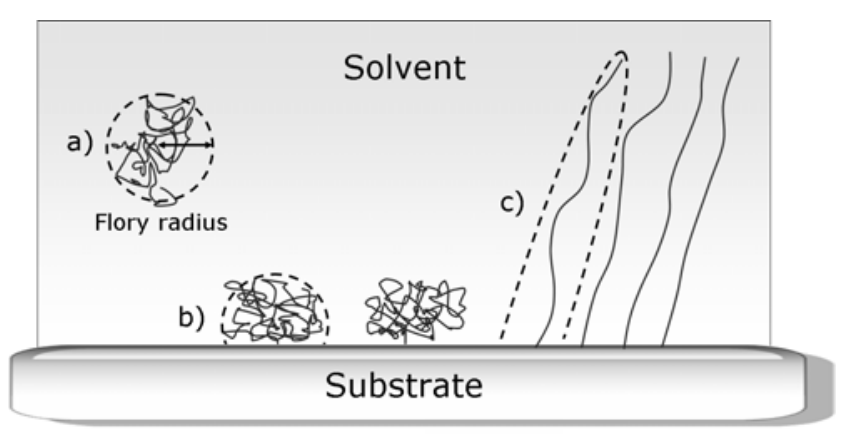

Figure 10 Schematic representation of end-grafting DNA molecules or other polymers from a solution onto a solid surface. a) Dissolved polymers adopt a coiled-up conformation with an average dimension described by the Flory radius. b) End-tethered polymers in a dilute layer adopt the mushroom conformation. c) Dense layer of end-tethered polymers, also referred to as a polymer brush.

bution function). Typically, aqueous solutions form a good solvent for DNA, governed by excluded-volume interactions (due to electrostatic repulsion): this is associated with a larger Flory radius. Experimentally it has been confirmed that the conformation of isolated DNA chains in aqueous solutions under physiological conditions follows $R_{\mathrm{g}} \sim L^{0.57}$ rather than $L^{0.5}$ [79]. The presence of electrolytes other than DNA (e.g. salt ions) in the solution will screen the intersegment repulsion, decreasing the Flory radius: $R_{\mathrm{g}} \sim L^{0.3}$ $[80,81]$.

DNA sensors involve probe layers of oligos that are end-tethered to the sensor surface, rather than dissolved freely in solution. An important distinction to be made here is between 'dilute' and 'dense' layers of end-tethered DNA. We will call the layer 'dilute' when the spacing, $D$, between neighboring DNA anchoring points is comparable to, or larger than $2 \cdot R_{\mathrm{g}}$, which implies that the strands cannot interact substantially (Fig. 10b). This polymer conformation is said to be mushroom-like. When the DNA is in a dense layer, with $D$ smaller than $2 \cdot R_{\mathrm{g}}$, the molecules do interact, and the conformation and orientation of the molecules can become strongly affected by these interactions (Fig. 10c). This type of polymer layer is called a polymer brush, as introduced by de Gennes [82, 83]. Clearly, apart from the layer density, also the DNA probe length is an important factor to be optimized in the development of a DNA sensor. For layers of short DNA $\left(L \sim l_{\mathrm{p}}\right)$ no coiling is expected. Instead, the molecules are almost straight and the steric interactions in case of a dense layer may result in a characteristic tilt angle, $\theta_{\text {tilt }}$.

3.2 DNA density and conformation on diamond

3.2.1 Nano-shaving The density, orientation and binding strength of DNA to mono- and polycrystalline diamond surfaces have been investigated by AFM measurements in buffer solutions [62, 84-86]. In particular, nano-shaving experiments are used: part of the functionalized surface is mapped by tapping mode AFM, then a 
smaller area is selected and scanned in contact mode AFM, removing the organic top-layer. By scanning the larger area once more in tapping mode, the height difference between the smaller, bare area and the surrounding, still functionalized parts can be established: this is the ds-DNA layer thickness $(T)$. For $16 \mathrm{bp}$ ds-DNA on top of a $15 \mathrm{~b}$ ss-DNA-tail attached to single crystalline diamond using the photo-chemical route in Fig. 7a, $T$ is found to range from $6.5 \mathrm{~nm}$ to $9.2 \mathrm{~nm}$ [86]. Combining this result with a simple geometric model, an interval of values for the tilt angle can be calculated: the tilt angle is estimated as Arc$\sin (T / L)$, with $L$ the stretched-out DNA length. Thus, by nano-shaving AFM experiments tilt angles of $30-36^{\circ}$ are found for $16 \mathrm{bp}$ ds-DNA on top of a $15 \mathrm{~b}$ ss-DNA-tail for dense layers on single crystalline diamond [62]. Shin et al. report a tilt angle of $46^{\circ}$ [62] for the same type of DNA immobilized with the electrochemical method of Fig. 9. With contact mode AFM, also the binding strength between the DNA layer and the diamond surface can be measured: the immobilization methods of Fig. 7a or Fig. 9 are compared and both yield covalent bonds [86].

Rezek et al. found a DNA coverage of $\sim 6 \times 10^{12}$ per $\mathrm{cm}^{2}$ for the photo-chemical method [86]. For comparison, a surface coverage of $\sim 2 \times 10^{14}$ linker molecules per $\mathrm{cm}^{2}$ is reported for the same immobilization method measured by XPS [62, 63]: so the result by Rezek et al. indicates that about $3 \%$ of the available linkers serves as an anchor for DNA. Elsewhere, a coverage of $\sim 1.8 \times 10^{10}$ DNA molecules per $\mathrm{cm}^{2}$ is reported for a different immobilization method [87]. There are $\sim 3 \times 10^{15}$ dangling bonds per area of $1 \mathrm{~cm}^{2}$ on an ideal, unreconstructed (100) crystal (Fig. 4a), but taking into account a ds-DNA cross-section of $\sim(2 \mathrm{~nm})^{2}$, only $\sim 2.5 \times 10^{13} \mathrm{ds}$-DNA molecules can fit on an area of $1 \mathrm{~cm}^{2}$. However, this absolute maximum coverage is not preferable: the biological functionality of the DNA molecules (hybridization and denaturation) decreases due to steric hinder. Thus, the reported value of $\sim 6 \times 10^{12}$ per $\mathrm{cm}^{2}$ is close to the theoretical maximum, and indicates sub-nanometer spacing between the dsDNA molecules.

3.2.2 IR and UV ellipsometry We investigated the optical properties of DNA brushes on diamond with spectroscopic ellipsometry (SE) [27]. Whereas ellipsometry using a fixed excitation wavelength is mainly used for determining layer thicknesses, SE allows for the calculation of more parameters, such as the optical constants (refractive index $\mathrm{n}$ and extinction coefficient $k$ ), the roughness and orientation of molecules [88]. We applied SE in the infrared (IR) and vacuum UV range to investigate the orientation of DNA layers on (U)NCD surfaces. So far, all surfaces have been measured in the dry phase; future measurements on DNA brushes submerged in buffer solutions are scheduled.

The signature of DNA in IR SE was first recorded on a sample containing a multilayer of $250 \mathrm{bp}$ ds-DNA $(0.2 \mu \mathrm{m}$ thick) adsorbed on NCD; the same spectral features could be identified for a monolayer of $250 \mathrm{~b}$ ss-DNA on NCD (prepared by the method of Fig. 7b), where the DNA layer thickness was found to be $40 \mathrm{~nm}$, or about one fourth of the stretched-out length of the molecules. For these highly flexible single strands coiling is expected, so a preferential orientation or specific tilt angle is not likely. Even for better organized layers of shorter DNA, the orientation could not be deduced based on IR SE alone, due to the complexity of the bands in the 'amide I' band (related to vibrations of amino and carbonyl groups [89, 90]).

Because measurements on thin, biological layers in the far UV require a synchrotron excitation source, the spectra have been collected at the BESSY II storage ring in Berlin (Germany). In this spectral range, the orientation calculation is achieved by a method originally developed by Silaghi et al. for guanine films on $\mathrm{Si}$ [91]: from the vacuum UV spectra, the components of $n$ and $k$ can be calculated for directions in- and out-of-plane of the diamond surface. Based on the electronic transition observed at $4.74 \mathrm{eV}$ (261 nm), originating from the $\pi-\pi^{*}$ transition dipole moments of the individual DNA bases, the average orientation of the bases can be calculated, and, perpendicular to that, the average tilt angle of the DNA molecules.

Unlike the layers of $250 \mathrm{~b}$ ss-DNA on NCD studied with IR SE, for layers of shorter DNA on UNCD (prepared as in Fig. 7b), some directional preference is likely, and we confirm the layers to be optically anisotropic. For the bestfit simulation of the $3.7 \mathrm{~nm}$ thick $8 \mathrm{~b}$ ss-DNA layer, we find an average tilt angle of $45^{\circ}$ with respect to the surface plane, for the $7.6 \mathrm{~nm}$ thick $36 \mathrm{~b}$ ss-DNA layer we observe an angle of $49^{\circ}$, and for the $10.8 \mathrm{~nm}$ thick $29 \mathrm{bp}$ ds-DNA (connected to an $\mathrm{A}_{7}$-ss-tail) layer we obtain an angle of $52^{\circ}$ (Fig. 11) [27]. The mean square error in the best-fit simulation was a factor of 3 better for these anisotropic conditions in comparison to an isotropic fit.

The values found here are comparable to those reported on Au surfaces: for $15 \mathrm{bp}$ ds-DNA an average tilt angle of $55-60^{\circ}$ with respect to the surface plane is found [92], and for 21-50 bp ds-DNA average tilt angles of 40$50^{\circ}$ from the surface are measured [93]. Yet, our values are larger than those already mentioned, obtained by nano-shaving AFM experiments [62] $\left(30-36^{\circ}\right.$ for $16 \mathrm{bp}$ ds-DNA on top of a 15 b ss-DNA-tail). If we apply the same geometrical analysis as in this article, where the tilt angle is estimated as $\operatorname{Arcsin}(T / L)$ with $T$ the DNA layer thickness and $L$ the DNA length, we get $50^{\circ}$ for $29 \mathrm{bp}$ ds-DNA connected to a $7 \mathrm{~b}$ ss-DNA-tail. For the flexible ss-DNA of $8 \mathrm{~b}$ and $36 \mathrm{~b}$, the assumption that the molecules are straight does not apply; the layer thickness is equal to two times the Flory radius of the molecules.

The reported tilt angles represent the average DNA orientation towards the plane of the surface on a macroscopic scale, but they are influenced both by the intermolecular arrangement, and the topography of the underlying UNCD surface. The initial UNCD surface with the UAlinker layer has an RMS roughness of $\sim 16 \mathrm{~nm}$, which is of the same order or larger than the stretched-out DNA 
a)

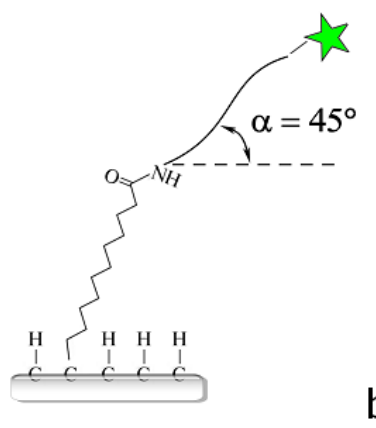

b)

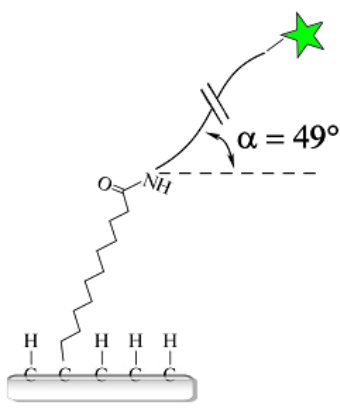

c)

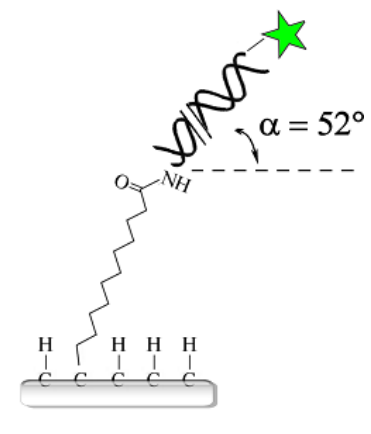

Figure 11 (online colour at: www.pss-a.com) Average tilt angles of DNA molecules on UNCD as calculated from UV SE: a) 8 b ss-DNA, b) 36 b ss-DNA, and c) 29 bp ds-DNA (connected to an $A_{7}$-ss-tail). Reprinted with permission from [27]. Copyright 2008 American Chemical Society.

lengths. To elucidate the influence of the surface roughness, additional measurements on atomically flat single crystalline diamond and Si surfaces are required. Thus, while the obtained tilt angles are not the final answer regarding the DNA orientation on CVD diamond surfaces, the analysis based on UV ellipsometry has proven to be a very elegant way of probing the DNA orientation directly, albeit on samples in vacuum. It was verified that the UV dose during the measurements did not influence the above results by unintended degradation of the DNA layers.

4 Read-out strategies for diamond-based biosensors The general goal of the diamond-based DNAsensor research is to develop a prototype biosensor for diagnostic purposes, based on DNA covalently attached to CVD diamond, with the same sensitivity and specificity as the commonly used methods, such as blotting techniques, and micro-arrays. Preferably, the detection would be faster (real-time) and cheaper (label-free and usable by nonspecialists) than these conventional methods [94].

Although different read-out strategies are available, we will focus on optical and electronic sensing, because these have provided the best results so far. Transparent transducer materials like glass and quartz, usually coated with poly-L-lysine, are interesting for biosensor applications with optical read-out (e.g. colorimetry or fluorescence), while conducting or semiconducting substrates like Au and $\mathrm{Si}$ allow electronic read-out (e.g. voltammetry, impedimetry or field effect transistor, FET, measurements). It will be shown that CVD diamond has favorable properties for both classes of measuring principles.

\subsection{Optical read-out}

4.1.1 Optical properties of CVD diamond First we will focus our attention on the spectral ranges where diamond is transparent; then we will look at the effects of its high refractive index.

Natural diamond was classified based on its optical ab sorption properties by Clark et al. in 1956 [95]. Roughly speaking, type I diamond contains a considerable amount of nitrogen $(\mathrm{N})$, giving the material a yellowish color, while type II does not. Sub-type II-a is very pure, transpar- ent diamond. All diamond, even type II-a, absorbs in the IR due to phonon processes [96]. One allowed (twophonon) process is the destruction of one phonon of $335 \mathrm{~cm}^{-1}$ and the creation of a second one of $1275 \mathrm{~cm}^{-1}$. Another allowed (three-phonon) process is the destruction of one and the creation of two phonons. They give rise to the absorption of diamond in the IR range between $4000 \mathrm{~cm}^{-1}$ to $1500 \mathrm{~cm}^{-1}(=2.5 \mu \mathrm{m}$ to $6.7 \mu \mathrm{m})$. The temperature dependence of this absorption has been studied in detail by Davies et al. [96]. For thin diamond windows and for low temperatures, the absorption is still reasonably low at the $10.6 \mu \mathrm{m}\left(934 \mathrm{~cm}^{-1}\right) \mathrm{CO}_{2}$-laser line [96]. IR photon absorption with the creation of only one phonon is forbidden by the inversion symmetry of the perfect diamond structure. Sub-type IIb is blue diamond containing boron, and this can exhibit additional absorption in the IR due to a one-phonon process [97].

All diamond also absorbs in the UV, which can be applied in diamond-based UV detectors [98]. Absorptions in this spectral region reflect the electronic structure of the dia mond bulk. In diamond, all four valence electrons of carbon are involved in creating bonds, whereas e.g. in graphite only three are required. This causes pure diamond to be an electrical insulator, whereas graphite is conductive (in the plane of the $\mathrm{sp}^{2}$-bonded sheets). The band gap of pure diamond at $5.47 \mathrm{eV}(227 \mathrm{~nm})$ is indirect, so apart from absorption of a UV photon, a phonon is required (Fig. 12a, [99]). Therefore, in UV-spectra the direct band gap at $7.3 \mathrm{eV}$ is more pronounced: Fig. 12b shows such a spectrum of (100) single crystalline CVD diamond, obtained at the synchrotron facilities of BESSY II, Berlin (Germany).

The optical properties of CVD diamond depend on doping and other parameters. Both n- and p-type doping of CVD diamond have been mastered, by introducing low concentrations of either $P$ (group $\mathrm{V}$ element with $5 \mathrm{VB}$ electrons, acting as an electron donor, producing a level around $0.6 \mathrm{eV}$ below the $\mathrm{CB}$ in bulk diamond) [100-102] or B (group III element with $3 \mathrm{VB}$ electrons, acting as a substitutional acceptor, producing a level around $0.37 \mathrm{eV}$ above the VB in bulk diamond) [103-105], respectively. Apart from blue (due to B-doping) and yellow (N-in- 

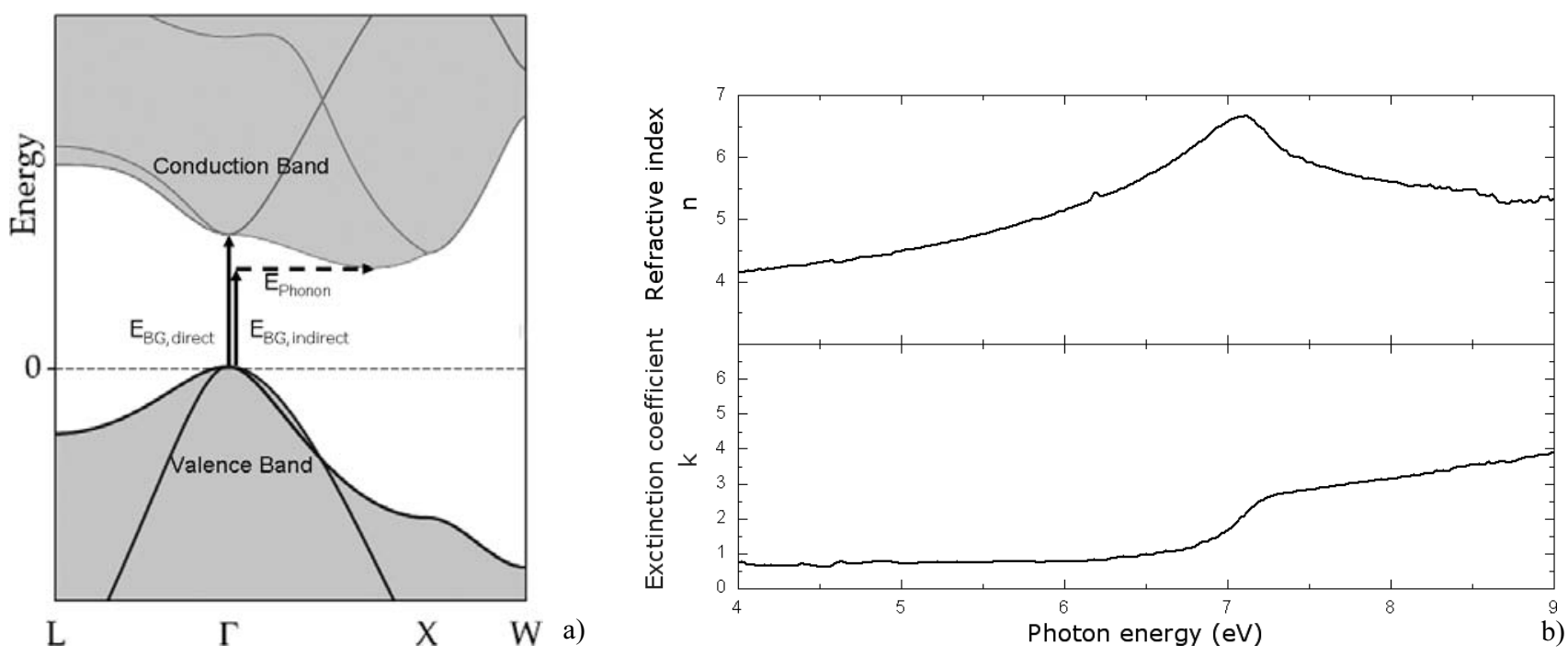

Figure 12 a) Calculated band energy diagram for the diamond bulk with indication of the direct and indirect band gap. (Adapted from [99].) b) Experimental vacuum UV spectra of (100) single crystalline CVD diamond showing the direct band gap above $7 \mathrm{eV}$.

corporation), more than hundred impurity-related defect centers in the diamond crystal lattice have been identified as $\mathrm{F}$ (arbe) (color) centers [97]. Most vacancy (V) defects are caused by another defect, like incorporation of an $\mathrm{N}$ atom: the $\mathrm{N}-\mathrm{V}$ defect is a very well-known color center, which fluoresces in the red with very good photo-stability. In case of vacancy defects, the color can be influenced by putting the diamond in a HPHT environment, thus reducing the lattice defects. In contrast, irradiation with highly energetic particles (fast neutrons, deuterons, $\gamma$-rays or $1-2 \mathrm{MeV}$ electrons) can be used to add defects, vacancies and interstitial atoms. Due to annealing at high temperature, the vacancies will be trapped at other defects, creating additional $F$ centers [106]. Ion implantation has a similar effect [97]. Also the grain boundaries in polycrystalline diamond will strongly influence the electronic and associated optical properties.

Diamond has a refractive index of $2.417 \mathrm{~nm}$ at $589 \mathrm{~nm}$ (yellow light) [107]. If we apply the Fresnel reflectivity formulas [108] to the case of a beam of $589 \mathrm{~nm}$ (yellow) light emitted in vacuum or air $\left(n_{1}=1\right)$ and shining onto a flat diamond surface $\left(n_{2}=2.417\right)$, we obtain the graph presented in Fig. 13. From the graph, we see that the reflectivity for $\mathrm{p}$-polarized light, $R_{\mathrm{p}}$, vanishes when the angle of incidence, $\theta_{\mathrm{i}}$, equals the Brewster angle (BA) $\arctan \left(n_{2} / n_{1}\right)$. In the case of diamond, this angle is $67.5^{\circ}$ for $589 \mathrm{~nm}$ light. Thus, a non-polarized beam that meets an interface at BA away from the surface normal will produce a purely s-polarized reflected beam. When the illumination comes from the diamond-side, the vanishing angle is the complement of the (external) BA.

For practical techniques that measure reflected light (e.g. IR reflectance spectroscopy), incidence angles higher than the BA are required, to have sufficient reflectivity of the p-polarized component (Fig. 13), but applying grazing angles of $\sim 80^{\circ}$ is quite difficult to work with in practice.
Alternatively, Remes et al. report interference-free reflectance-absorbance spectroscopy under BA configuration (BA-RAS) using p-polarized IR light to study thin UA, DNA and organosilane polymer layers on NCD [109]. While the high refractive index of diamond makes it difficult to use techniques based on external reflection, the opposite is true for techniques based on internal reflection. This can be seen from the critical angle, $\theta_{\mathrm{c}}=\arcsin \left(n_{1} / n_{2}\right)$, which gives the condition for total internal reflection [110]. In case of a diamond surface in air and $581 \mathrm{~nm}$ light, $\theta_{\mathrm{c}}$ has a low value of $24.4^{\circ}$. This is used in the cut of diamond gemstones, to maximize their brilliance at the top facet [110], and can be applied in attenuated total reflection (ATR) spectroscopy: under $\theta_{\mathrm{i}}>\theta_{\mathrm{c}}$ conditions, a standing electromagnetic wave exists at the crystal sample interface, which is exponentially vanishing and therefore called an evanescent wave [111]. Another example is defocused

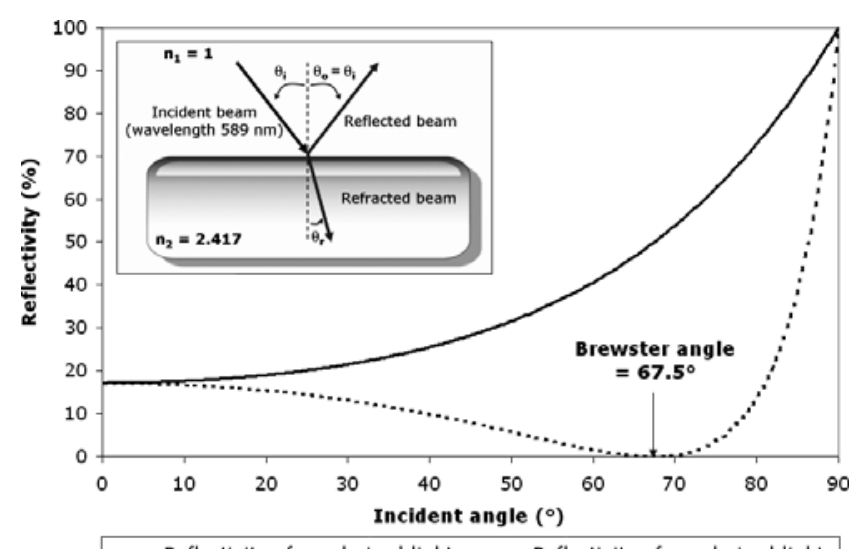

Figure 13 Calculated reflectivity of s- and p-polarized $589 \mathrm{~nm}$ light upon reflection on a diamond surface in vacuum or air. The inset figure shows the corresponding optical model. 
single molecule fluorescence imaging, used to investigate molecular orientation: this technique is usually applied on glass [112], but would in principle benefit from using diamond [52]. Techniques based on evanescent waves are typically very surface sensitive, implying that diamond is an interesting material for such optical sensing techniques.

For applications of diamond in optical biosensors, we sum up that the material is highly transparent in a wide range around the visible spectrum: from $227 \mathrm{~nm}$ to $2.5 \mu \mathrm{m}$, as well as above $6.7 \mu \mathrm{m}$. This transparency is combined with a high refractive index. So diamond is an ideal material for optical probing from the backside, or with BA-RAS using p-polarized light.

4.1.2 Fluorescence-based DNA sensing on diamond Before the results of fluorimetric DNA sensing ex periments are discussed, some remarks are to be made regarding the imaging of fluorescently labeled DNA layers on diamond by confocal microscopy. Imaging the DNA layers in buffer solutions was found to be a crucial improvement [59]: due to better refractive index matching, fluorescence emission towards the detection side is increased and hindering reflection is reduced. Of course, prevention of drying the surface is also beneficial for the functionality of the DNA layer. In case of doubt, fluorescence can be readily distinguished from residual reflection light by photo-bleaching of a small region on the surface. When using $488 \mathrm{~nm}$ excitation (Ar-ion laser line), it is noted that Alexa Fluor 488 is a much brighter and stable label for this application than FITC.

In [59], probe ss-DNA of $36 \mathrm{~b}$ was attached to NCD and UNCD according to the method in Fig. 7b. Hybridization was evaluated using Alexa Fluor 488-labeled target ss-DNA of $29 \mathrm{~b}$, which was either perfectly complementary to, or contained a 1-mismatch with the probe layer (Fig. 14).

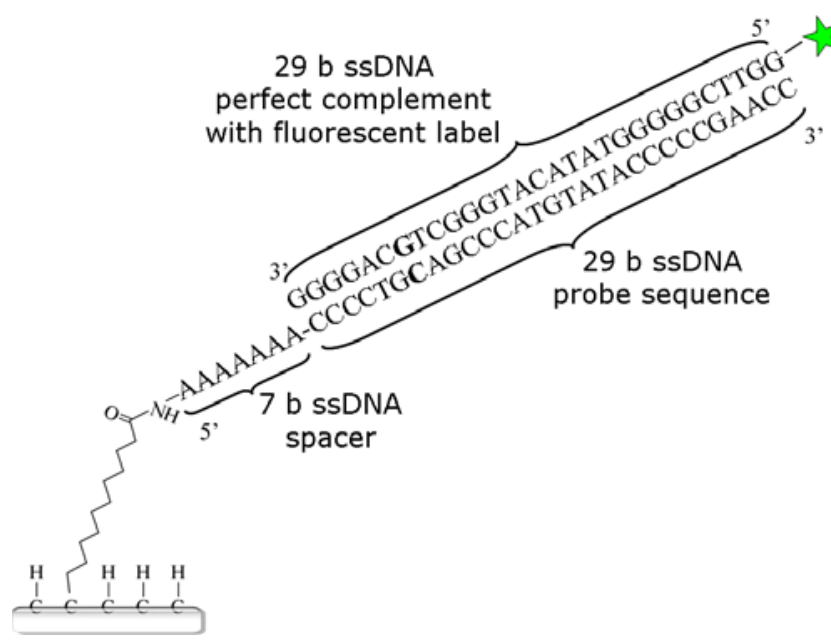

Figure 14 (online colour at: www.pss-a.com) Base sequence of the $29 \mathrm{bp}$ dsDNA (connected to an $A_{7}$-ss-tail) used for optical and electronic SNP detection. The SNP target ss-DNA had the same sequence as the perfect complement, except for the $\mathrm{G}$ indicated in bold: this nucleotide was replaced with a C. (Not drawn to scale.)
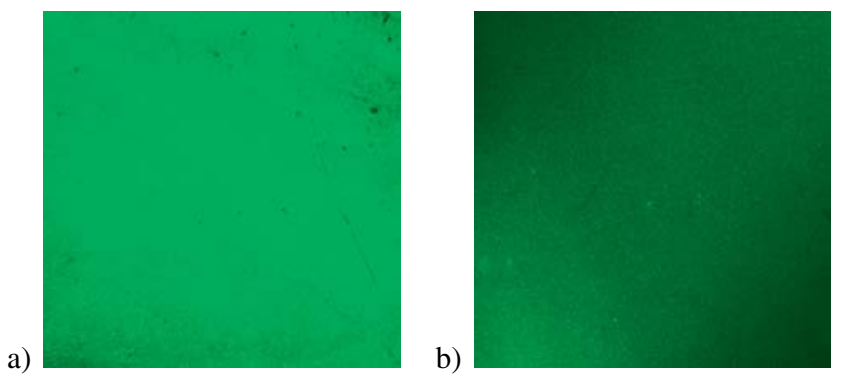

Figure 15 (online colour at: www.pss-a.com) Confocal fluorescence images of NCD samples with $36 \mathrm{~b}$ probe ss-DNA after hybridization with $29 \mathrm{~b}$ target ss-DNA, carrying an Alexa Fluor 488-label: a) complementary target and b) 1-mismatch target. Both images show an area of $(900 \mu \mathrm{m})^{2}$.

The effect of different hybridization conditions and stringency washings was investigated. The amount of hybridization was then monitored by fluorescence under the confocal fluorescence microscope. The best contrast in hybridization with complementary or 1-mismatch target ss-DNA was reproducibly obtained for hybridization of $600 \mathrm{pmol} / \mathrm{cm}^{2}$ target ssDNA at $80{ }^{\circ} \mathrm{C}$ in Microhyb hybridization buffer and two stringency washings in $0.2 \times \mathrm{SSC}$ at $75^{\circ} \mathrm{C}$ and at RT, respectively. Fluorescence images taken after the optimal hybridization contrast conditions can be seen in Fig. 15. Thus, end-point SNP-sensitivity of a CVD diamond-based DNA sensor has been demonstrated using optical read-out.

\subsection{Electronic read-out}

4.2.1 Electronic properties of CVD diamond As discussed in Section 4.1.1, pure diamond is a good insulator, but $\mathrm{p}$ - and n-type semiconductivity can be achieved via doping during the CVD process. Semiconducting and insulating diamond films can both play an important role in electronic biosensors. Also H-terminated diamond surfaces are very interesting for application in electronic biosensors.

One type of electronic biosensors employs the fieldeffect in semiconducting substrates, such as doped Si [113-115] and doped diamond [116]. The results of these FET-like devices depend sensitively on the details of the experimental setup, as reviewed by Poghossian et al. [117]. Several specific factors have been identified that jeopardize a reproducible and sensitive field-effect-based DNA sensor [118, 119]: the drift of the measured signal, the variable distance of the DNA molecules from the surface due to the attachment via long linker molecules, and the effect of counter-ions screening the DNA charge-effect. The latter problem can be avoided by measuring in a low-ionic buffer $[119,120]$. However, hybridization requires cations in the buffer so that only end-point measurements can be performed using low-ionic buffers. A solution is proposed by Vermeeren et al. [94] (see Section 4.2.2).

In electrolyte-diamond-insulator-semiconductor (EDIS) biosensors [121], typically a thin layer of undoped CVD diamond is deposited on $\mathrm{SiO}_{2}$-covered p-type $\mathrm{Si}$. In this 


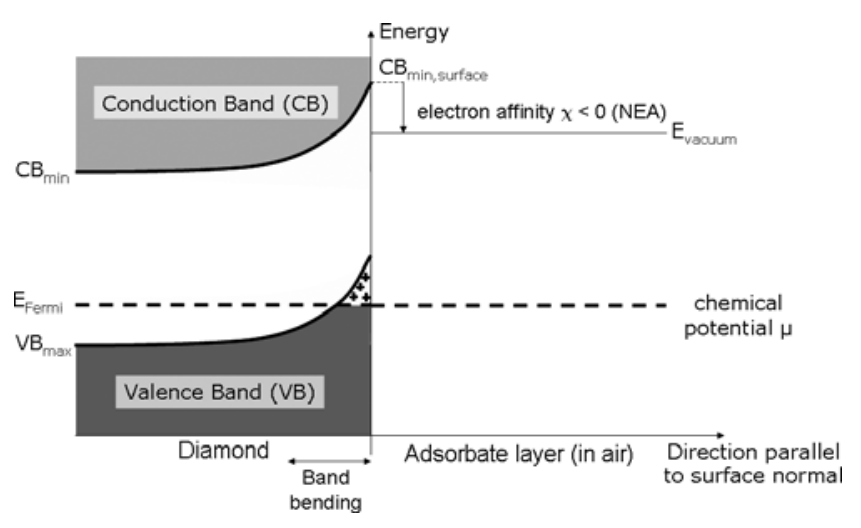

Figure 16 Schematic band diagram of H-terminated diamond in air with upward band bending and negative electron affinity (NEA).

case, the diamond serves as the biocompatible interface, while the field effects probably arise in the underlying Si. EDIS sensors can be operated in 'ConCap' mode, keeping the capacitance of the sensor constant using a feedbackcircuit, while measuring the voltage change [122]. With this configuration, a $\mathrm{pH}$-sensor [123] and a capacitive penicillin biosensor with high sensitivity (70 $\mathrm{mV} /$ decade) and low detection limit $(5 \mu \mathrm{M})[124]$ have been realized. In principle, sandwich-structures of undoped diamond deposited on top of doped diamond would have even better properties: the field effect would arise in the underlying semiconducting diamond (instead of Si).

Whereas these sandwich-structured field effect biosensors use bulk properties of diamond (semiconducting or insulating), we now turn to the unique electronic properties of the diamond surface, allowing simple, planar FET-structures (similar to those on Si, see e.g. [120]). The $\mathrm{H}$-terminated diamond surface exhibits negative electron affinity (NEA). It comes about due to the higher electron affinity of carbon as compared to hydrogen, giving rise to $\mathrm{C}^{\delta-}-\mathrm{H}^{\delta+}$ dipoles at the surface of $\mathrm{H}$-terminated diamond [125]. This causes upward band bending in a thin, nearsurface layer inside the diamond (Fig. 16). Since oxygen has a higher electron affinity than carbon, the surface dipoles on oxidized diamond are oriented opposite as compared to H-termination: $\mathrm{C}^{\delta+}-\mathrm{O}^{\delta}$. The $\mathrm{CB}$ minimum is below the vacuum level, corresponding to positive electron affinity (PEA). The surface of $\mathrm{H}$-terminated diamond can become conductive: it is agreed upon that apart from NEA, the adsorption of a thin layer of atmospheric water is essential for this effect [126]. Following the 'transfer doping model' of Maier et al. [126], holes are injected by acceptors located at the surface (instead of inside another host lattice, which is the common transfer doping process). The importance of the planar, p-type conductivity of $\mathrm{H}$-terminated diamond lies in the fact that this surfaces can be used for $\mathrm{pH}$-sensing, as reported by Kawarada et al. [127], Garrido et al. [128], and Nebel et al. [131]. In a recent paper, Dankerl et al. point out that this type of $\mathrm{pH}$-sensors should not be described by transfer doping, and special care has to be taken regarding the choice of the counter electrode material [129]: in that case a weak $\mathrm{pH}$-sensitivity of $\sim+5 \mathrm{mV} / \mathrm{pH}$ is observed. Apart from pure $\mathrm{pH}$-sensing, H-terminated diamond surfaces can be employed for electronic biosensing. Thus, FET-like devices do not necessarily require bulk semiconductivity by doping, but can be based on the planar p-type semiconductivity of hydrogenated diamond surfaces: the conductivity of the surface depends on the presence of charged molecules (DNA) near the surface.

Most electrode surfaces in aqueous solutions are vulnerable to hydrolysis if a certain bias voltage is crossed: the voltages lower than this threshold are called the "potential window' of the electrode. B-doped diamond shows a wide potential window together with a low background current [130]. This also depends on the surface termination: F-terminated diamond is found to have a larger potential window than H-terminated surfaces. It should be noted that these values apply to single crystalline diamond, whereas in biosensor applications typically (U)NCD is used, which does not have these ideal properties [131].

In summary, electronic read-out of diamond-based biosensors is an excellent option, because of the favorable and tunable electronic properties of CVD diamond, combined with its good stability in electrolytes. DNA is a polyelectrolyte and can be detected by field effect devices (based on the bulk semiconductivity of doped diamond, or the surface conductivity of H-terminated diamond). Yet, uncharged biomolecules may be detected as well: EDIS sensors are highly sensitive for capacitive effects.

4.2.2 Impedance-based DNA sensing on diamond Impedance spectroscopy in principle allows for real-time and label-free testing. The electronic read-out of DNA hybridization and denaturation on B-doped CVD diamond surfaces is reported by Yang et al. [116]: cyclic voltammetry (in a redox solution) and impedance spectroscopy (in standard hybridization buffer) are applied to study the probe ss-DNA layers $(31 \mathrm{~b})$, prepared according to Fig. 7a, before and after hybridization with perfectly complementary and 4b-mismatched target ssDNA (both $16 \mathrm{~b})$. The impedance at high $(>10 \mathrm{kHz})$ and very low $(<1 \mathrm{~Hz})$ frequencies is found to decrease in both cases, but more pronounced for the perfect match. Upon denaturation, the original spectrum is observed again. The impedance change upon hybridization is attributed to the field effect of the additional negative charges (of the backbones of the target DNA) influencing the band structure of the underlying p-type semiconducting diamond. An equivalent circuit model for the diamond/interface/solution combination is proposed, consisting of a series of respectively: a resistor in parallel with a constant-phase element, a resistor in parallel with a capacitance, and a resistor.

We have also reported the use of impedance spectroscopy for DNA sensing on CVD diamond [94]: in this case the probe ss-DNA ( $36 \mathrm{~b})$ layers were prepared with the immobilization method of Fig. 7b. The spectra are fitted 


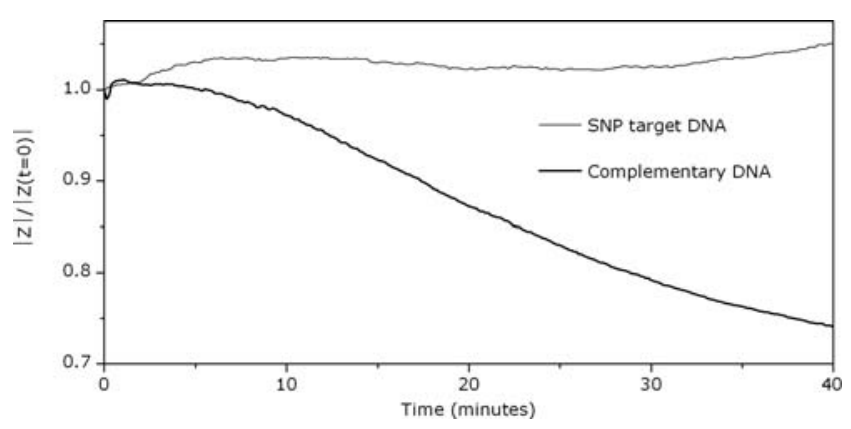

Figure 17 Real-time and label-free impedance spectroscopy measurement during hybridization of perfectly complementary and 1-mismatch DNA: temporal evolution of the impedance at $1150 \mathrm{~Hz}$.

to the previously mentioned equivalent circuit model proposed by [116]. In this paper the difference between hybridization with a perfect complement and 1-mismatch (Fig. 14) are compared: the cases can be discriminated, thus SNP-sensitivity is demonstrated. Moreover, this type of detection is fast: the perfect complement case can be distinguished from the 1-mismatch case within five minutes (Fig. 17). Also the kinetics of DNA denaturation is investigated, by monitoring the impedance at high frequencies $(\sim 1 \mathrm{MHz})$. In this range, the impedance is mainly determined by the solution resistance. Upon denaturation, DNA and its associated counter-ions are released from the surface into the solution, thereby increasing the amount of mobile charges. The change of the solution resistance is found to decrease exponentially, and the exponential decay time is longest in case of perfect complementary strands. It is argued that this possibility to observe denaturation dynamically can be applied to identify new DNA mutations; it is possible that even the type of defect can be inferred from the detailed analysis of the temporal behavior.

4.3 Acoustic sensors As illustrated in the review of Mortet et al. [132], CVD diamond can be used for acoustic devices with excellent properties. Diamond does not show piezoelectricity, but diamond combined with a suitable piezoelectric material, such as $\mathrm{ZnO}$ or AlN, is a good choice for high frequency applications, because - due to the high density and stiffness of diamond - acoustic waves travel through the material with a very high group velocity. Examples are wireless devices in which surface acoustic wave (SAW) GHz filters are used based on CVD diamond. Regarding sensing applications, acoustic sensors can detect variations of mechanical stress, temperature, damping and mass-loading. Applied to DNA sensing, they could detect hybridization and denaturation by sensing the respective increase and decrease of mass on the surface. One approach is based on the idea of the quartzcrystal microbalance (QCM): a diamond-based microbalance was recently realized by Williams et al. [133], using langasite $\left(\mathrm{La}_{3} \mathrm{Ga}_{5} \mathrm{SiO}_{14}\right)$ as the piezoelectric material, sandwiched between gold electrodes and an NCD top-layer.
Also other acoustic devices may be adapted for DNA sensing, such as micro-cantilevers and flexural plate wave sensors using diamond-membranes [132]. In a recent study by Tsortos et al., acoustic quartz sensors have been used to investigate the conformation of dsDNA molecules [134]. Although this type of read-out would in principle work even better with diamond, no actual results of diamondbased prototype devices have been reported in literature yet.

5 Conclusions We argue that CVD diamond forms an excellent transducer material for DNA sensors. This platform material is non-corrosive - even in solution - and biocompatible. Diamond can be functionalized using various strategies, and allows for optical, electronic and acoustic read-out.

Coupling biomolecules to diamond utilizing the strong carbon-carbon bond, gives us the opportunity of obtaining a highly stable biosensor. Moreover, the covalent attachment of probe ss-DNA to diamond can be achieved by a straightforward protocol. A particularly fruitful approach is the covalent coupling of organic linkers with tunable length. Using the functional group at the distal end of these linkers, DNA (and various other biomolecules) can be immobilized on the diamond surface. Sensor surfaces prepared in this way have been demonstrated to show SNP-sensitivity and good reusability.

For optical sensing, diamond has the advantage of being transparent over a broad spectral range, while its high refractive index favors techniques based on internal reflection. For electronic sensing, diamond offers different options. Undoped diamond can be used in the EDIS set-up to measure capacitive effects; FET-sensors require either p- or n-type bulk diamond, which can be produced by applying dopants during the CVD process, or p-type surface conductivity of H-terminated diamond. DNA sensors are to be used in vitro only, thus they only require a biocompatible top-layer, to which the probe DNA is anchored and where interaction with target DNA samples takes place. Therefore, CVD diamond-coated Si wafers in particular are a good platform material, since they are easier to produce and cheaper than an all-diamond biosensor.

The next stage in the development of diamond-based DNA sensors requires miniaturization, to lower the amount of sample fluids required and to allow for parallel measurements, an important advantage of standard genetic tests based on micro-arrays. Arraying of the sensor surface, which is a prerequisite for high-throughput biosensors, can be conveniently arranged by photo-patterning of the linker layer. If this next hurdle is taken, the advantages that CVD diamond has to offer in the field of biosensors - i.e. realtime and label-free measurements - can be benefitted from in practical applications.

Acknowledgements This work was supported by IWTSBO (project \#030219 'CVD Diamond: a novel multifunctional material for high temperature electronics, high power/high 
frequency electronics and bioelectronics'), FWO-WOG (WO.035.04N 'Hybrid Systems at Nanometer Scale'), the IUAPP6/42 program 'Quantum Effects in Clusters and Nanowires', the European Community - Research Infrastructure Action under the FP6 "Structuring the European Research Area" Programme (through the Integrated Infrastructure Initiative "Integrating Activity on Synchroton and Free Electron Laser Science - Contract RII 3-CT-2004-506008"), the project "Synchrotron-Ellipsometry in the UV to EUV", No. 05 KS4KTB/3 of the German Federal Ministry of Education and Research (BMBF), and the Life Sciences Impulse Program of the transnationale Universiteit Limburg. S.W. is a postdoctoral research fellow of the Research Foundation - Flanders (FWO-Vlaanderen) and V.V. is an IWT postdoctoral fellow.

The authors thank following colleagues. At the Institute for Materials Research, Hasselt University: M. Daenen and Dr. O. A. Williams for deposition of CVD diamond, and Dr. O. Douhéret for tapping mode AFM measurements. At the Institute for Surface Analysis, Berlin: C. Werner, Dr. S. D. Pop, Dr. C. Cobet, and Prof. N. Esser for UV SE measurements, and Dr. K. Roodenko and Dr. K. Hinrichs for IR SE measurements.

\section{References}

[1] D. L. Hartl and E. W. Jones, Essential Genetics, A Genomics Perspective, 3rd ed. (Jones \& Bartlett, New York, 2002), p. 145.

[2] F. Davis, A. V. Nabok, and S. P. J. Higson, Biosens. Bioelectron. 20, 1153 (2005).

[3] F. Davis, A. H. Margaret, A. R. Cossins, and S. P. J. Higson, Anal. Chem. 79, 1531 (2007)

[4] R. Webster and P. G. Read (eds.), Gems: Their Sources, Descriptions and Identification, 5th ed. (ButterworthHeinemann, London, 2000).

[5] J. C. Angus, H. C. Will, and W. S. Stanko, J. Appl. Phys. 39, 2915 (1968).

[6] E. Kohn, P. Gluche, and M. Adamschik, Diam. Relat. Mater. 8, 934 (1999).

[7] F. J. H. Guillen, K. Janischowsky, J. Kusterer, W. Ebert, and E. Kohn, Diam. Relat. Mater. 14, 411 (2005).

[8] P. W. May, Philos. Trans. R. Soc. London A 358, 473 (2000).

[9] J. E. Field (ed.), The Properties of Natural and Synthetic Diamond (Academic Press, London, 1992).

[10] L. S. Pan and D. R. Kania (eds.), Diamond: Electronic Properties and Applications (Kluwer, Boston, 1995).

[11] M. A. Prelas, G. Popovici, and G. K. Bigelow (eds.), Handbook of Industrial Diamonds and Diamond Films (Marcel Dekker, New York, 1998).

[12] C. E. Nebel and J. Ristein (eds.), Thin Film Diamond II, Semiconductors and Semimetals, Vol. 77 (Elsevier, 2004).

[13] D. M. Gruen, O. A. Shenderova, and A. Y. Vul (eds.), Synthesis, Properties and Applications of Ultrananocrystalline Diamond (Springer Verlag, Dordrecht, 2005).

[14] S. Mitura, A. Mitura, P. Niedzielski, and P. Couvrat, in: Nanotechnology in Materials Science, edited by S. Mitura (Pergamon Press, Elsevier, 2000).

[15] L. Tang, C. Tsai, W. W. Gerberich, L. Kruckeberg, and D. R. Kania, Biomaterials 16, 483 (1995).
[16] P. Aspenberg, A. Anttila, Y. T. Konttinen, R. Lappalainen, S. B. Goodman, L. Nordsletten, and S. Santavirta, Biomaterials $\mathbf{1 7}, 807$ (1996).

[17] K. Bakowicz and S. Mitura, J. Wide Bandgap Mater. 9, 261 (2002).

[18] W. Okrój, M. Kamińska, L. Klimek, W. Szymański, and B. Walkowiak, Diam. Relat. Mater. 15, 1535 (2006).

[19] A. M. Schrand, H. Huang, C. Carlson, J. J. Schlager, E. Ohsawa, S. M. Hussain, and L. Dai, J. Phys. Chem. B 111, 2 (2007).

[20] W. Yang, O. Auciello, J. E. Butler, W. Cai, J. A. Carlisle, J. E. Gerbi, D. M. Gruen, T. Knickerbocker, T. L. Lasseter, J. N. Jr. Russell, L. M. Smith, and R. J. Hamers, Nature Mater. 1, 253 (2002).

[21] P. Christiaens, V. Vermeeren, S. Wenmackers, M. Daenen, K. Haenen, M. Nesládek, M. vandeVen, M. Ameloot, L. Michiels, and P. Wagner, Biosens. Bioelectron. 22, 170 (2006).

[22] J. C. Kotz and P. M. Treichel, Chemistry and Chemical Reactivity, 5th ed. (Saunders College Publishing, New York, 1999).

[23] Y. L. Yang, L. M. Struck, L. F. Sutcu, and M. P. D'Evelyn, Thin Solid Films 225, 203 (1993).

[24] C. Pandey, Phys. Rev. B 25, 4338 (1982).

[25] L. Ostrovskaya, V. Perevertailo, V. Ralchenko, A. Dementjev, and O. Loginova, Diamond Relat. Mater. 11, 845 (2002).

[26] S. Wenmackers, P. Christiaens, W. Deferme, M. Daenen, K. Haenen, M. Nesládek, P. Wagner, V. Vermeeren, L. Michiels, M. vandeVen, M. Ameloot, J. Wouters, L. Naelaerts, and Z. Mekhalif, Mater. Sci. Forum 492/493, 267 (2005).

[27] S. Wenmackers, S. D. Pop, K. Roodenko, V. Vermeeren, O. A. Williams, M. Daenen, O. Douhéret, J. D'Haen, A. Hardy, M. K. Van Bael, K. Hinrichs, C. Cobet, M. vandeVen, M. Ameloot, K. Haenen, L. Michiels, N. Esser, and P. Wagner, Langmuir 24, 7269 (2008).

[28] M. Tachiki, T. Fukuda, K. Sugata, H. Seo, H. Umezawa, and H. Kawarada, Jpn. J. Appl. Phys. 39, 4631 (2000).

[29] B. Rezek, C. Sauerer, J. A. Garrido, C. E. Nebel, and M. Stutzmann, Appl. Phys. Lett. 82, 3336 (2003).

[30] C. Toma, A. Volodin, G. Bogdan, W. Deferme, K. Haenen, M. Neslàdek, and C. Van Haesendonck, Phys. Status Solidi A 204, 2920 (2007).

[31] T. Ando, J. Tanaka, M. Ishii, M. Kamo, Y. Sato, N. Ohashi, and S. Shimosaki, J. Chem. Soc. Faraday Trans. 89, 3105 (1993).

[32] K. Larsson, H. Björkman, and K. Hjort, J. Appl. Phys. 2, $1026(2001)$

[33] C. Q. Sun, H. Xie, W. Zhang, H. Ye, and P. Hing, J. Phys. D, Appl. Phys. 33, 2196 (2000).

[34] J. Chen, S. Z. Deng, J. Chen, Z. X. Yu, and N. S. Xu, Appl. Phys. Lett. 74, 3651 (1999).

[35] C. Y. Fong and B. M. Klein, in: Diamond: Electronic Properties and Applications, edited by L. S. Pan and D. R. Kania (Kluwer, Boston, 1995).

[36] S. J. Sque, R. Jones, and P. R. Briddon, Phys. Status Solidi A 202, 2091 (2005).

[37] C. H. Goeting, F. Marken, A. R. Osborn, R. G. Compton, and J. S. Foord, Electrochem. Solid State Lett. 4, E29 (2001). 
[38] A. Freedman, J. Appl. Phys. 75, 3112 (1994).

[39] T. I. Hukka, T. A. Pakkanen, and M. P. D’Evelyn, J. Phys. Chem. 99, 4710 (1995).

[40] S. Hadenfeldt and C. Benndorf, Surf. Sci. 402-404, 227 (1998).

[41] J. B. Miller and D. W. Brown, Diam. Relat. Mater. 4, 435 (1995).

[42] J. B. Miller and D. W. Brown, Langmuir 12, 5809 (1996).

[43] J. B. Miller, Surf. Sci. 439, 21 (1999).

[44] T. Ando, K. Yamamoto, M. Kamo, Y. Sato, Y. Takamatsu, S. Kawasaki, F. Okino, and H. Touhara, J. Chem. Soc. Faraday Trans. 91, 3209 (1995).

[45] T. Ando, M. Nishitani-Gamo, R. E. Rawles, K. Yamamoto, M. Kamo, and Y. Sato, Diamo. Relat. Mater. 5, 1136 (1996).

[46] J. A. Chaney and C. S. Feigerle, Surf. Sci. 425, 245 (1999).

[47] K.-I. Sotowa, T. Amamoto, A. Sobana, K. Kusakabe, and T. Imato, Diam. Relat. Mater. 13, 145 (2004).

[48] Y. Ikeda, T. Saito, K. Kusakabe, S. Morooka, H. Maeda, Y. Taniguchi, and Y. Fujiwara, Diam. Relat. Mater. 7, 830 (1998).

[49] T. Tsubota, S. Ida, O. Hirabayashi, S. Nagaoka, S. Nagayama, M. Nagata, and Y. Matsumoto, J. Ceram. Soc. Jpn. 110, 904 (2002).

[50] K. Ushizawa, Y. Sato, T. Mitsumori, T. Machinami, T. Ueda, and T. Ando, Chem. Phys. Lett. 351, 105 (2002).

[51] S. Wenmackers, K. Haenen, M. Nesládek, P. Wagner, L. Michiels, M. vandeVen, and M. Ameloot, Phys. Status Solidi A 199, 44 (2003).

[52] S. Wenmackers, Morphology, Functionality and Molecular Conformation Study of CVD Diamond Surfaces Functionalised with Organic Linkers and DNA, Ph.D. dissertation, Hasselt University (2008).

[53] T. Strother, T. Knickerbocker, J. N. Russell, Jr., J. E. Butler, L. M. Smith, and R. J. Hamers, Langmuir 18, 968 (2002).

[54] M. R. Linford and C. E. D. Chidsey, J. Am. Chem. Soc. 115, 12631 (1993).

[55] M. R. Linford, P. Fenter, P. M. Eisenberger, and C. E. D. Chidsey, J. Am. Chem. Soc. 117, 3145 (1995).

[56] A. B. Sieval, A. L. Demirel, J. W. M. Nissink, M. R. Linford, J. H. van der Maas, W. H. de Jeu, H. Zuilhof, and E. J. R. Sudhölter, Langmuir 14, 1759 (1998).

[57] F. Effenberger, G. Gotz, B. Bidlingmaier, and M. Wezstein, Angew. Chem. Int. Ed. 37, 2462 (1998).

[58] S. Wenmackers, P. Christiaens, M. Daenen, K. Haenen, M. Nesládek, M. vandeVen, V. Vermeeren, L. Michiels, M. Ameloot, and P. Wagner, Phys. Status Solidi A 202, $2212(2005)$.

[59] V. Vermeeren, S. Wenmackers, M. Daenen, K. Haenen, O. A. Williams, M. Ameloot, M. vandeVen, P. Wagner, and L. Michiels, Langmuir, DOI: 10.1021/la800946v (in press).

[60] A. B. Steel, R. L. Levicky, T. M. Herne, and M. J. Tarlov, Biophys. J. 79, 975 (2000).

[61] Y. L. Zhong, K. F. Chong, P. W. May, Z.-K. Chen, and K. P. Loh, Langmuir 23, 5824 (2007).

[62] D. Shin, B. Rezek, N. Tokuda, D. Takeushi, H. Watanabe, T. Nakamura, T. Yamamoto, and C. E. Nebel, Phys. Status Solidi A 203, 3245 (2006).

[63] B. M. Nichols, J. E. Butler, J. N. Russell, Jr., and R. J. Hamers, J. Phys. Chem. B 109, 20938 (2005).
[64] T.-C. Kuo, R. L. McCreery, and G. M. Swain, Electrochem. Solid State Lett. 2, 288 (1999).

[65] B. Azambre, S. Collura, and J. V. Weber, Diam. Relat. Mater. 14, 1311 (2005).

[66] W. Yang, S. E. Baker, J. E. Butler, C.-S. Lee, J. N. Russell, Jr., L. Shang, B. Sun, and R. J. Hamers, Chem. Mater. 17, 938 (2005).

[67] G. Shul, P. Actis, B. Marcus, M. Opallo, R. Boukherroub, and S. Szunerits, Diam. Relat. Mater., DOI 10.1016/ j.diamond.2007.12.007 (in press).

[68] E. Fortin, J. Chane-Tune, D. Delabouglise, P. Bouvier, T. Livache, P. Mailley, B. Marcus, M. Mermoux, J.-P. Petit, S. Szunerits, and E. Vieil, Electroanalysis 17, 517 (2005).

[69] S. Szunerits and R. Boukherroub, J. Solid State Electrochem., DOI 10.1007/s10008-007-0473-3 (in press).

[70] W. Yang, J. E. Butler, J. N. Russell, Jr., and R. J. Hamers, Analyst 132, 296 (2007).

[71] A. Härtl, E. Schmich, J. E. Garrido, J. Hernando, S. C. R. Catharino, S. Walter, P. Feulner, A. Kromka, D. Steinmüller, and M. Stutzmann, Nature Mater. 3, 736 (2004).

[72] K. S. Song, M. Degawa, Y. Nakamura, H. Kanazawa, H. Umezawa, and H. Kawarada, Jpn. J. Appl. Phys. Part 2 43, L814 (2004).

[73] J. Hernando, T. Pourrostami, J. A. Garrido, O. A. Williams, D. M. Gruen, A. Kromka, D. Steinmüller, and M. Stutzmann, Diam. Relat. Mater. 16, 138 (2007).

[74] O. Kratky and G. Porod, Reci. Trav. Chim. Pays-Bas 68, 1106 (1949).

[75] B. Tinland, A. Pluen, J. Sturm, and G. Weill, Macromolecules 30, 5763 (1997).

[76] J. B. Mills, E. Vacano, and P. J. Hagerman, J. Mol. Biol. 285, 245 (1999)

[77] P. J. Hagerman, Annu. Rev. Biophys. Biophys. Chem. 17, 265 (1988).

[78] P. J. Flory, Principles of Polymer Chemistry (Cornell University Press, Ithaca-New York, 1953).

[79] R. Lehner, J. Koota, G. Maret, and T. Gisler, Phys. Rev. Lett. 96, 107801-4 (2006).

[80] D. W. Schaefer, C. J. Brinker, D. Richter, B. Farago, and B. Frick, Phys. Rev. Lett. 64, 2316 (1990).

[81] M. Doi and E. Edwards, The Theory of Polymer Dynamics (Oxford University Press, New York, 1992).

[82] P. G. de Gennes, Adv. Colloid Interface Sci. 27, 189 (1987).

[83] P. G. de Gennes, in: Physical Basis of Cell-Cell Adhesion, edited by P. Bongrand (CRC Press, Boca Raton-Florida, 1988).

[84] B. Rezek, D. Shin, T. Nakamura, and C. E. Nebel, J. Am. Chem. Soc. 128, 3884 (2006).

[85] C. E. Nebel, H. Uetsuka, B. Rezek, D. Shin, N. N. Tokuda, and T. Nakamura, Diam. Relat. Mater. 16, 1648 (2007).

[86] B. Rezek, D. Shin, H. Uetsuka, and C. E. Nebel, Phys. Status Solidi A 204, 2888 (2007).

[87] K. Takahashi, M. Tanga, O. Takai, and H. Okamura, Diam. Relat. Mater. 12, 572 (2003).

[88] K. Hinrichs, S. D. Silaghi, C. Cobet, N. Esser, and D. R. T. Zahn, Phys. Status Solidi B 242, 2681 (2005).

[89] S. Moses, S. H. Brewer, L. B. Lowe, S. E. Lappi, L. B. Gilvey, M. Sauthier, R. C. Tenent, D. L. Feldheim, and S. Franzen, Langmuir 20, 11134 (2004). 
[90] C. Lee, K. H. Park, and M. Cho, J. Chem. Phys. 125, 114508 (2006).

[91] S. D. Silaghi, M. Friedrich, C. Cobet, N. Esser, W. Braun, and D. R. T. Zahn, Phys. Status Solidi B 242, 3047 (2005).

[92] A. Anne and C. Demaille, J. Am. Chem. Soc. 128, 542 (2006).

[93] L. Moiseev, M. S. Ünlü, A. K. Swan, B. B. Goldberg, and C. R. Cantor, Proc. Natl. Acad. Sci. USA. 103, 2623 (2006).

[94] V. Vermeeren, N. Bijnens, S. Wenmackers, M. Daenen, K. Haenen, O. A. Williams, M. Ameloot, M. vandeVen, P. Wagner, and L. Michiels, Langmuir 23, 13193 (2007).

[95] C. D. Clark, R. W. Ditchburn, and H. B. Dyer, Proc. R. Soc. London A 234, 363 (1956).

[96] G. Davies, A. Mainwood, C. Piccirillo, K. L. Lewis, T. P. Mollart, M. Nesládek, and Z. Remes, Phys. Status Solidi A 193, 442 (2002).

[97] W. Zhu, in: Diamond - Electronic Properties and Applications, edited by L. S. Pan and D. R. Kania (Kluwer, Boston, 1995).

[98] E. Monroy, F. Omnès, and F. Calle, Semicond. Sci. Technol. 18, R33 (2003).

[99] S. J. Sque, A First-Principles Study on Bulk and Transfer Doping of Diamond, PhD dissertation, University of Exeter (2007).

[100] S. Koizumi, M. Kamo, Y. Sato, H. Ozaki, and T. Inuzuka, J. Appl. Phys. 71, 1065 (1997)

[101] S. Koizumi, T. Teraji, and H. Kanda, Diam. Relat. Mater. 9, 935 (2000).

[102] M. Nesládek, Semicond. Sci. Technol. 20, R19 (2005).

[103] M. W. Geis and J. C. Angus, Sci. Am. 267, 84 (1992).

[104] S. Yamanaka, D. Takeuchi, H. Watanabe, H. Okushi, and K. Kajimura, Diam. Relat. Mater. 9, 956 (2000).

[105] J. Teraji, M. Hamada, H. Wada, M. Yamamoto, K. Arima, and T. Ito, Diam. Relat. Mater. 14, 255 (2005).

[106] A. T. Collins, Phys. B 185, 284 (1993).

[107] D. F. Edwards and E. Ochoa, J. Opt. Soc. Am. 71, 607 (1981).

[108] C. Lheveder, J. Meunier, and S. Hénon, in: Physical Chemistry of Biological Interfaces, edited by A. Baszkin and W. Norde (Marcel Dekker, New York, 2000).

[109] Z. Remes, A. Kromka, H. Kozak, M. Vanecek, K. Haenen, and S. Wenmackers, Diam. Relat. Mater. (submitted).

[110] H. D. Young and R. A. Freedman, University Physics, 12th ed. (Pearson Addison-Wesley, San Francisco, 2008).

[111] R. A. Dluhy, in: Physical Chemistry of Biological Interfaces, edited by A. Baszkin and W. Norde (Marcel Dekker, New York, 2000).

[112] M. Böhmer and J. Enderlein, J. Opt. Soc. Am. B 20, 554 (2003).

[113] E. Souteyrand, J. P. Cloarec, J. R. Martin, C. Wilson, I. Lawrence, S. Mikkelsen, and M. F. Lawrence, J. Phys. Chem. B 101, 2980 (1997).
[114] J. Fritz, E. B. Cooper, S. Gaudet, P. K. Sorger, and S. R. Manalis, Proc. Natl. Acad. Sci. USA 99, 14142 (2002).

[115] F. Uslu, S. Ingebrandt, D. Mayer, S. Böcker-Meffert, M. Odenthal, and A. Offenhäusser, Biosens. Bioelectron. 19, 1723 (2004).

[116] W. Yang, J. E. Butler, J. N. Russell, Jr., and R. J. Hamers, Langmuir 20, 6778 (2004).

[117] A. Poghossian, A. Cherstvy, S. Ingebrandt, A. Offenhäusser, and M. J. Schöning, Sens. Actuators B 111/112, 470 (2005).

[118] M. J. Schöning and A. Poghossian, Electroanalysis 18 1893 (2006).

[119] S. Ingebrandt and A. Offenhäusser, Phys. Status Solidi A 203, 3399 (2006).

[120] S. Ingebrandt, Y. Han, F. Nakamura, A. Poghossian, M. J. Schöning, and A. Offenhäusser, Biosens. Bioelectron. 22, 2834 (2007)

[121] M. H. Abouzar, A. Poghossian, A. Razavi, O. A. Williams, N. Bijnens, P. Wagner, and M. J. Schöning, Biosens. Bioelectron. (accepted).

[122] A. Poghossian, M. H. Abouzar, M. Sakkari, T. Kassab, Y. Han, S. Ingebrandt, A. Offenhäusser, and M. J. Schöning, Sens. Actuators B, Chem. 118, 163 (2006).

[123] P. Christiaens, M. H. Abouzar, A. Poghossian, T. Wagner, N. Bijnens, O. A. Williams, M. Daenen, K. Haenen, O. Douhéret, J. D’Haen, Z. Mekhalif, M. J. Schöning, and P. Wagner, Phys. Status Solidi A 204, 2925 (2007).

[124] M. H. Abouzar, A. Poghossian, A. Razavi, A. Besmehn, O. A. Williams, K. Haenen, P. Wagner, and M. J. Schöning, Phys. Status Solidi A (in press).

[125] J. B. Cui, J. Ristein, and L. Ley, Phys. Rev. Lett. 81, 429 (1998).

[126] F. Maier, M. Riedel, B. Mantel, J. Ristein, and L. Ley, Phys. Rev. Lett. 85, 3472 (2000).

[127] H. Kawarada, Y. Araki, T. Sakai, T. Ogawa, and H. Umezawa, Phys. Status Solidi A 185, 79 (2001).

[128] J. A. Garrido, A. Härtl, S. Kuch, M. Stutzmann, O. A. Williams, and R. B. Jackman, Appl. Phys. Lett. 86, 073504 (2005)

[129] M. Dankerl, A. Reitinger, M. Stutzmann and J. A. Garrido, Phys. Status Solidi RRL 2, 31 (2008).

[130] T. Kondo, K. Honda, D. A. Tryk, and A. Fujishima, Electrochim. Acta 48, 2739 (2003).

[131] C. E. Nebel, B. Rezek, D. Shin, and H. Watanabe, Phys. Status Solidi A 203, 3273 (2007).

[132] V. Mortet, O. A. Williams, and K. Haenen, Phys. Status Solidi A 205, 1009 (2008).

[133] O. A. Williams, V. Mortet, M. Daenen, and K. Haenen, Appl. Phys. Lett. 90, 063514 (2007).

[134] A. Tsortos, G. Papadakis, K. Mitsakakis, K. A. Melzak, and E. Gizeli, Biophys. J. 94, 2706 (2008) 